\title{
LOS TESTIMONIOS MONUMENTALES ROMANOS DE L'ALMISERÀ (VILLAJOYOSA, ALICANTE) Y SU RELACIÓN CON LA TORRE FUNERARIA DE SANT JOSEP
}

\author{
MONUMENTAL ROMAN TESTIMONIES IN L'ALMISSERÀ (VILLAJOYOSA, ALICANTE) \\ AND THEIR CONNNECTION TO THE FUNERARY TOWER OF SANT JOSEP
}

\author{
ANTONIO SELLÉS RODRÍGUEZ \\ ANTONIO ESPINOSA RUIZ \\ Vilamuseu. Red de Museos y \\ Monumentos de Villajoyosa
}

\section{INTRODUCCIÓN}

Este artículo se basa en el trabajo de fin de grado de Historia presentado por Antonio Sellés en el Departamento de Prehistoria, Arqueología, Historia Antigua, Filología Griega y Filología Latina de la Universidad de Alicante en junio de 2014, dirigido por Antonio Espinosa. El trabajo venía a abordar un asunto pendiente de la investigación arqueológica local: los sillares recuperados de los alrededores de la finca $\mathrm{La} \mathrm{Cam-}$ paneta y trasladados a los jardines del Centro Social de Villajoyosa, donde hoy se conservan y exhiben al público. La posterior preparación de este artículo ha llevado a encadenar una serie de hipótesis que pueden resolver algunas de las incógnitas pendientes sobre la torre funeraria romana de Sant Josep (Abad y Bendala, 1985; Ruiz y Charquero, 2014), monumento al que Diego Ruiz y Ana Charquero dedican otro artículo de este mismo número de la revista Lucentum.

La entidad del yacimiento de La Campaneta guarda relación con cuestiones como la perduración del poblamiento y la toponimia romana en la Alta Edad Media en la Marina Baixa, una comarca natural bien definida que sin duda constituyó el territorium de la ciudad romana subyacente a la actual Villajoyosa.

Hemos abordado la interpretación de los testimonios materiales atestiguados en la zona, así como la significación y el origen del conocido como «monumento de l'Almiserá», a la vez que hemos buscado paralelos y propuesto una interpretación funcional y tipológica, ahondando en el vaciado de la bibliografía antigua por si ésta pudiera arrojar alguna luz.

Queremos agradecer su ayuda en diferentes aspectos de este trabajo al personal de Vilamuseu, y en particular al entonces concejal de Patrimonio Histórico, José Lloret, por las facilidades brindadas desde la concejalía para realizar esta investigación; a los Dres. Lorenzo Abad, Juan Manuel Abascal y Sonia Gutiérrez por resolver amablemente las dudas que les hemos planteado, proponernos algunas puntualizaciones y sugerirnos algunas lecturas adicionales; y a los Dres.
Fernando Prados, Jesús Moratalla e Ignasi Grau por sus sugerencias como miembros del tribunal del trabajo de fin de grado. Mención especial merece la colaboración del arqueólogo municipal de Villajoyosa, Diego Ruiz, y de la arqueóloga Ana $\mathrm{M}^{\mathrm{a}}$ Charquero, que nos han facilitado los dibujos más recientes de la Torre de Sant Josep y de las piezas pertenecientes a los pedestales del entorno del monumento, además de discutir con nosotros las hipótesis que ofrecemos en este artículo, y que en realidad hemos de compartir con ellos, ya que son fruto de un trabajo en equipo que se adscribe dentro del proyecto Villajoyosa Romana: de la República a la Antigüedad Tardía, que codirigen los mencionados Dres. Lorenzo Abad, Sonia Gutiérrez y Ignasi Grau del Área de Arqueología de la Universidad de Alicante y los arqueólogos de Vilamuseu Diego Ruiz y Amanda Marcos. Este proyecto ha supuesto, desde 2008, la excavación, recuperación y restauración integral del monumento y de la mayor parte de su entorno, y que nos ha proporcionado gran cantidad de nuevas piezas arquitectónicas y de información que ahora podemos cruzar con otros testimonios como los de la vecina partida de l'Almiserà.

EL CONTEXTO ARQUEOLÓGICO: EL MUNICIPIUM ROMANO DE ALLON (VILLAJOYOSA) Y SU TERRITORIUM

No vamos a detenernos en esta cuestión, abordada con detalle en diferentes publicaciones recientes (Espinosa, 2006; Frías, 2010; Espinosa, Ruiz y Marcos, 2011, 154-173; Espinosa, Ruiz y Marcos, 2014, 179-197).

Baste recordar que, actualmente, la mayoría de los investigadores consideran que la antigua ciudad de Allon, citada en diferentes formas por las fuentes clásicas (Alonís, Alonai, Allon, Ad Leones, etc.) es el núcleo urbano romano subyacente a la actual Villajoyosa (provincia de Alicante, España), atestiguado tanto por la epigrafía (así, la inscripción dedicada al duunviro y flamen Quinto Manlio Celsino, CIL II, 3571; o la 
conmemorativa de la restauración de un macellum, CIL II, 3570) como por diferentes hitos monumentales propios de una ciudad y su entorno, entre los cuales destacan las termas públicas monumentales de la calle Canalejas (Ruiz, 2010; Espinosa, Ruiz y Marcos, 2011, 154-173). Las evidencias arqueológicas y textuales, conjugadas, dejan poco lugar a la duda, a pesar de que falta la prueba epigráfica: parece claro que este topónimo antiguo corresponde a un núcleo privilegiado entre Lucentum y Dianium, y el de Villajoyosa es el único documentado y el centro de la comarca natural flanqueada por los territorios de esas dos ciudades.

Precisamente, el hito más importante para la investigación arqueológica de este municipium ha sido el descubrimiento de las mencionadas termas en el año 2006. Este hallazgo demostraba que el núcleo urbano romano se encontraba debajo de la actual ciudad de Villajoyosa y no en los alrededores de la Torre de Sant Josep o en los de la villa de Xauxelles, como se había planteado anteriormente. Respecto a la localización del foro, creemos que se situaba bajo la actual Plaza de la Generalitat, dado que unos sondeos realizados en 2011-2012 ${ }^{1}$ dieron a conocer la existencia de rellenos intencionales hacia el último cuarto del s. I, momento en el cual la ciudad romana de Villajoyosa tuvo un auge urbanístico y de estructuración territorial después de otorgársele la categoría de municipium ${ }^{2}$. La existencia de grandes sillares en los muros exteriores de la capilla de Santa Marta (a escasos metros de la plaza de la Generalitat), así como en los de contención de las tierras donde se encontraba el castillo medieval, demuestran que durante la Edad Moderna los monumentos romanos sirvieron de cantera para las nuevas construcciones de la villa de Vilajoiosa.

En su tesis doctoral, uno de nosotros analizó los diferentes niveles en los que se estructuraba el poblamiento romano imperial de la Marina Baixa (Espinosa, 1996a). Por debajo del núcleo urbano del municipium se detectaban varios núcleos secundarios, que proponía identificar con vici. Tenían determinadas características comunes: importante extensión superficial; ubicación en la llanura litoral, junto a la vía que discurría en paralelo a la costa o a un camino secundario hacia los valles del interior de la comarca; necrópolis propia; epigrafía mayor (en los casos de cronología anterior al s. III, lo que no sucede en l'Albir); una larga duración en el tiempo; la asociación a las mejores y más extensas tierras de cultivo y a importantes manantiales o, en el caso de tierras sin agua (como l'Albir), a un acueducto; e indefectiblemente, la asociación con una villa rural, alrededor de la cual crecieron hasta

1. Información proporcionada por Diego Ruiz y Amanda Marcos, Vilamuseu (Sección Municipal de Arqueología, Etnografía y Museos de Villajoyosa).

2. La ciudad romana de Villajoyosa obtuvo la categoría de $m u$ nicipium hacia 73/74 d. C., con el Edicto de Vespasiano, según Géza Alföldy $(2003,35-58)$. alcanzar dimensiones semiurbanas. Sería el caso de La Pila (Altea), l'Albir (Alfaz del Pi) y probablemente el área de l'Almiserà (Villajoyosa), en este último caso sin una propuesta concreta de ubicación hasta la fecha. También podría ser el caso de Xauxelles (junto al barrio de La Ermita de San Antonio, en Villajoyosa). Es probable que la entidad de algunos de ellos estuviera formalizada mediante la figura del magister, un magistrado dependiente de la ciudad (Espinosa, Ruiz y Marcos, 2011, 169; Abascal y Espinosa, 1989).

\section{TURRIS?}

Centrémonos ahora en la zona de l'Almiserà, donde Antonio Espinosa (1996a) proponía la existencia de uno de los vici de la comarca. Analicemos en primer lugar una cuestión relativa a la toponimia menor. En los siglos XIII y XIV las crónicas cristianas citan una alquería islámica llamada Torres, muy vinculada a la de Orcheta (población interior situada a $9 \mathrm{~km}$ al norte de Villajoyosa). Posiblemente tendría algún tipo de fortificación, ya que se menciona el 'Castro de Torres' en 1324 (Coromines, 1997, 311). La villa de Vilajoiosa todavía no había sido fundada, y su futuro emplazamiento costero dependía también de Orcheta, como se desprende del hecho de que en marzo de 1277 el rey Pedro el Grande se quejó de que en esta población se habían armado barcas que atacaban a los cristianos (Galiana, 2012, 133).

La toponimia actual no deja dudas al respecto a la ubicación de Torres (Fig. 1): tenemos el río de ese mismo nombre a $3 \mathrm{~km}$ al este de Villajoyosa, y por tanto lo razonable es buscar la alquería de Torres en sus proximidades. Espinosa ya propuso en su Tesis doctoral (1996a, passim) su identificación con las alquerías islámicas de l'Almiserà, ubicadas en el curso medio del río, así como el origen romano tanto del topónimo como del poblamiento asociado. No obstante, hay que tener en cuenta que también podría derivar del vocablo árabe turra, 'margen, límite' (Coromines, 1997, 310).

Las prospecciones realizadas en el año 2000 en la partida de l'Almiserà con motivo de la urbanización de la zona certificaron el hallazgo de tres alquerías muy cercanas entre sí (Tossal de l'Almiserà, Foietes Dalt y l'Alfarella) y una pequeña mezquita rodeada de necrópolis junto a la primera de ellas (García Gandía et alii, 2004). Estas alquerías forman un grupo que se desarrolla desde al menos el s. X hasta la conquista cristiana, y sin duda podemos relacionarlo con el topónimo que nos interesa. Lo que no está tan claro hasta el momento es la ubicación del poblamiento romano que las originó, cuyo nombre pudo ser Turris. La investigación exhaustiva realizada en 2005 sobre el terreno de la partida de Torres en el curso bajo del río, con kilómetros de sondeos sistemáticos en las tierras llanas que rodean a la torre funeraria de Sant Josep (s. II), descartó un poblamiento imperial o tardoantiguo de entidad, más allá de una fábrica bajo imperial de material de 


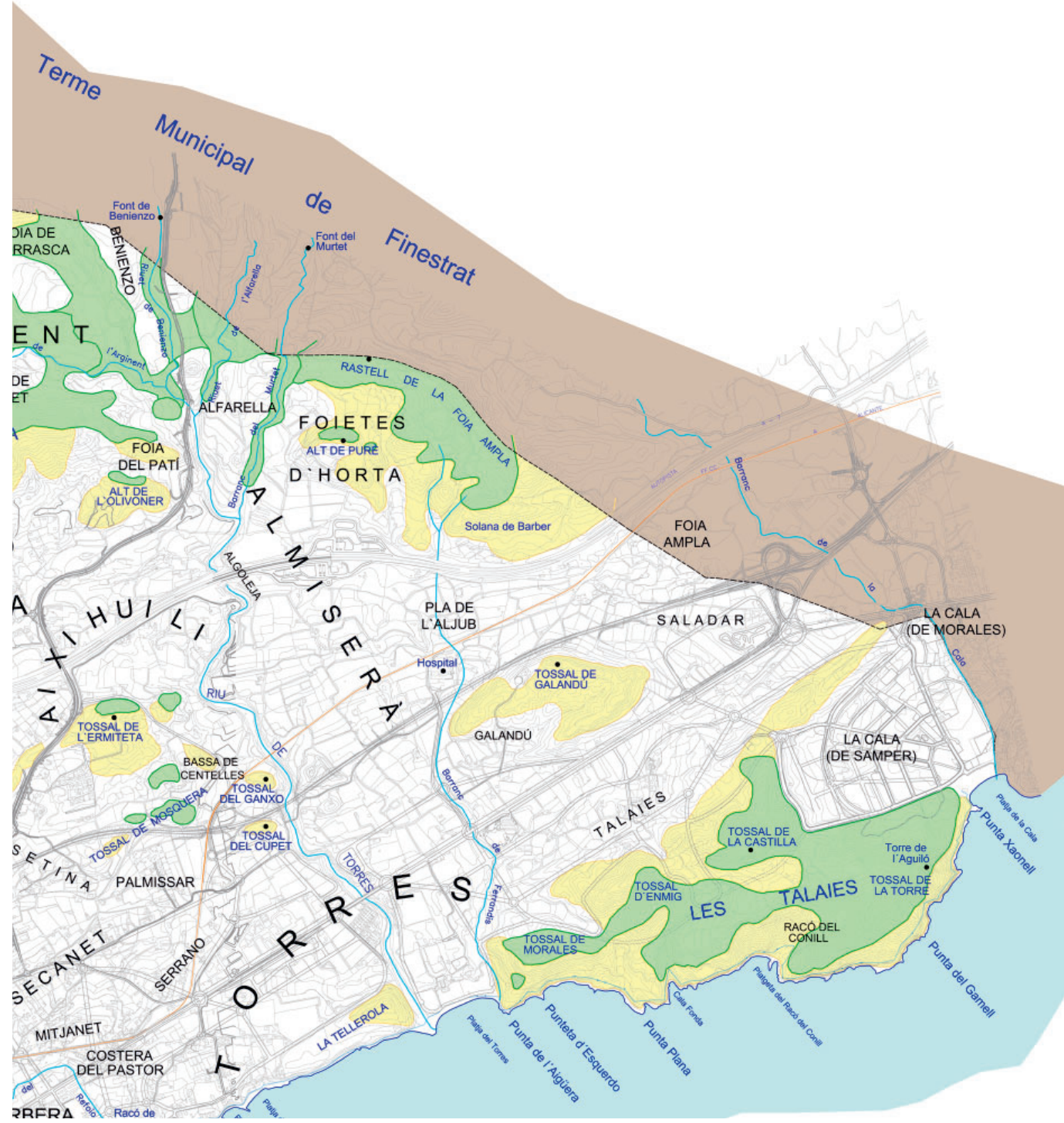

Figura 1: Plano parcial de las partidas rurales de Villajoyosa (Galiana, 2011, 792).

construcción y dolios (Espinosa, Ruiz y Marcos, 2014, 94) y quizá una pequeña villa. Por tanto, hay que trasladar la búsqueda más al norte, siguiendo el curso del río. A este respecto, como vamos a ver, el núcleo romano más relevante es el yacimiento de La Campaneta, bajo una antigua masía que se encuentra dentro de la gran partida de l'Almiserà, a escasa distancia de los yacimientos islámicos que hemos mencionado (Fig. 2).

El origen del topónimo latino podría guardar relación con la erección de la Torre de Sant Josep en el s. II sobre el talud costero de la playa del río Torres. Era un hito que se veía claramente desde gran parte del valle de este río, desde luego desde el núcleo de La Campaneta; y por supuesto desde el mar, lo que ayudaría a la fijación del topónimo: no es algo tan frecuente la ubicación de una torre de esta envergadura en una posición aislada y tan destacada en el paisaje litoral. No obstante, el asentamiento romano más relevante de la zona debió estar localizado en el curso medio y no en el curso bajo del río Torres (Espinosa, 2006, 234-242), se islamizaría especialmente a partir del s. X y perduraría hasta el siglo XIII.

Queremos ahora traer a colación un dato epigráfico que merece ser tenido en cuenta en la hipótesis que estamos argumentando: Josep Corell (1999, 181182) afirma que en una columna de la Iglesia de la Asunción de Villajoyosa había una inscripción (CIL II, 1433, con bibliografía antigua) dedicada al Genio Turri(s) (Fig. 3). Se basa en una mención del Antiquissimus y otras fuentes de finales de. $\mathrm{s}$. XV y comienzos del XVI, como Carbonell (ms. 1492) o el Codex Filonardianus (ms. s. XVI), que sitúan la pieza «in villa Zolosa/Tholosa». Estos topónimos, ligeramente deformados según Corell, no corresponderían en su opinión a Tolox (Málaga), como propuso Hübner; sino a Villajoyosa. La argumentación de Josep Corell respecto a la procedencia del epígrafe es en todo caso aceptada por Xavier Espluga (2009a, 228 y 2009b, 142-143), aunque en uno de sus trabajos $(2009 \mathrm{~b}, 142)$ afirma que, aunque «por lo general es considerada auténtica» 


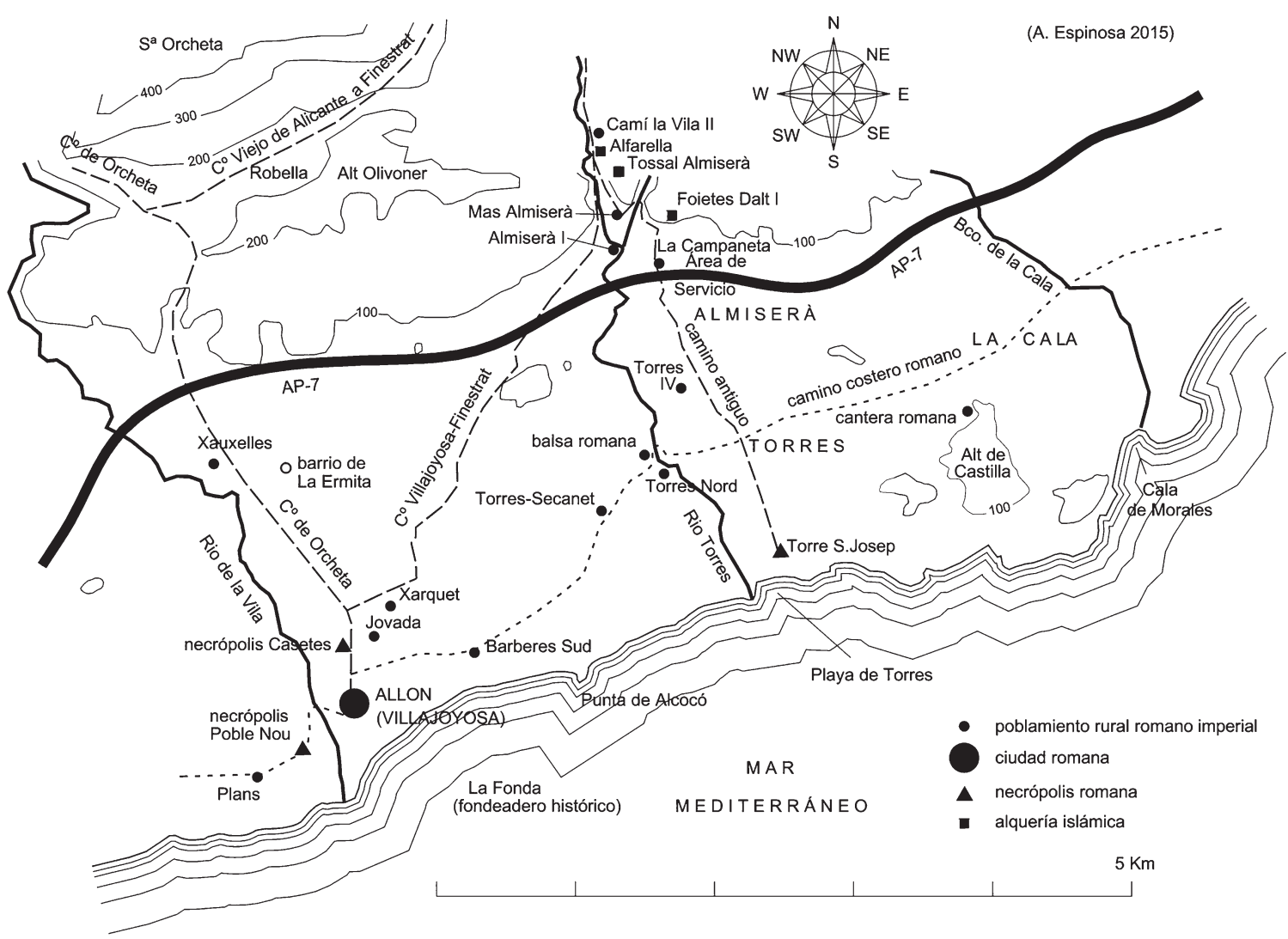

Figura 2: Principales yacimientos romanos imperiales e islámicos mencionados en el artículo, en la llanura costera de Villajoyosa (adaptado de Espinosa, 2006, 232).

la pieza es en su opinión suspecta, es decir, «con visos de ser falsa».

A este respecto, la falta del original impide ir más allá en la resolución de la cuestión de la autenticidad o falsedad de este ara epigráfica. La ausencia de dedicante no es habitual, pero no faltan ejemplos próximos que podemos presentar como paralelo: así, por traer un ejemplo, el ara dedicada a Venus Genetrix hallada en 1981 en Valentia y expuesta en el Centre Arqueolòic de l'Almoina (Ribera, 1983, 66; Corell, 1999, 62) (CIL

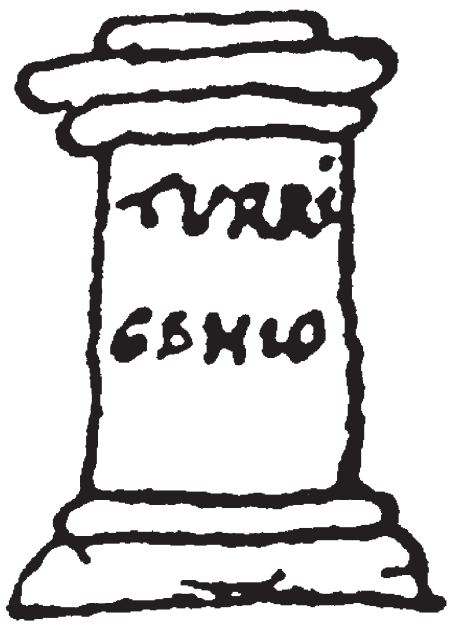

Figura 3: Inscripción dedicada al Genio de Turris según el dibujo del Filonardianus (Corell, 1999, 182).
II2/14,10 = AE 1987, 704e), en la que aparece escuetamente la fórmula Veneri Genetrici.

Aceptando la atribución a Villajoyosa, y en el caso de que la pieza fuese auténtica, lo más lógico es pensar que procede del área urbana de la ciudad romana, quizá del propio del foro de Allon, situado con toda probabilidad en la actual plaza de la Generalitat, a escasos metros de la Iglesia de la Asunción, en uno de cuyos pilares se encontraba.

Las fuentes que mencionan esta pieza son muy antiguas: de hecho, son anteriores a la destrucción de las murallas y de la iglesia antigua de Villajoyosa a manos de una escuadra corsaria turca, ocurrida en 1443, por lo que no es probable que esta inscripción continúe en los pilares de la actual iglesia, construida a mediados del s. XVI sobre las ruinas de la anterior. No sabemos qué ocurrió con la pieza, aunque pudo reaprovecharse en la nueva obra, como otros epígrafes, pero no necesariamente a la vista (si lo está, podría encontrarse tras la capa de enlucido que cubre la mayor parte de los paramentos interiores del templo). Convendrá, por tanto, estar atentos por si una futura restauración interior del edificio la sacase a la luz.

Josep Corell la traduce como «Al genio de la torre». Otra opción creemos que podría ser «(Dedicado) al genio de Turris» (Espinosa, 2008, 118). El genius loci era la divinidad que velaba por el destino de un lugar o población concreto, cualquiera que fuera su estatus jurídico (Fuchs, 1960, 810-811). En el caso de Allon (y 
siempre, insistimos, que la pieza no sea falsa) no sería descabellado pensar que este Turri(s) se refiera a uno de los barrios o vici del municipium, y concretamente al que pudo dar nombre al río de Torres y a la alquería islámica (Espinosa, 2006, 242-243, reseñado en HEp $\left.15,2006,4, n^{\circ} 6\right)$. La coincidencia de la atribución a Villajoyosa de una inscripción dedicada al Genius Turris y la existencia de un topónimo islámico Turris de posible origen romano merece dejar la cuestión abierta en espera de nuevos datos.

Entre los yacimientos romanos imperiales localizados en el curso del río Torres destaca La Campaneta (Espinosa, 1989, 29-36; Espinosa, 1996a, 316-318). Como hemos apuntado más arriba, se encuentra debajo y en torno a la finca de este nombre, situada junto al Área de Servicio La Marina de la autopista A-7, entre los Km 655 y 656. Durante la construcción de esta infraestructura en los años setenta se localizaron varios sillares de grandes dimensiones, algunos de los cuales parece que quedaron cubiertos por su terraplén.

José Payá Nicolau, fundador del Museo Etnográfico de Villajoyosa, comunicó a Espinosa, a mediados de los años ochenta, la existencia de un sillar moldurado reutilizado como umbral en una construcción. Durante la visita al lugar se localizaron materiales cerámicos en superficie, fechables al menos desde el cambio de Era hasta el s. IV d. C. En los años siguientes se constató la existencia de un muro de doble paramento de $75 \mathrm{~cm}$ de grosor revestido de signinum en una de sus caras, sin duda parte de un depósito de agua de grandes dimensiones.

La prospección del yacimiento en los años 20012002, realizada por José Ramón García, aportó, según el informe de la intervención, un número considerable de materiales en superficie, con una cronología que iba desde época altoimperial hasta mediados del siglo III d. C. Entre ellos destacan sigillatas sudgálicas y africanas, cerámica común, ánforas, fragmentos de dolia y restos de elementos de construcción (sillares y restos de tegulae). Estos sondeos no descubrieron ninguna estructura, a excepción de líneas de muro muy deterioradas (García Gandía et alii, 2001). Años más tarde, unos sondeos para un gasoducto detectaron una gran potencia estratigráfica a escasos metros al norte de la casa o mas de La Campaneta, y sacaron a la luz un sillar de grandes dimensiones que se trasladó al parque de Barberes Sur ${ }^{3}$ (Fig. 13).

$\mathrm{Si}$ hacemos un breve repaso a los yacimientos romanos de la zona, tenemos:

- Almiserà I: Yacimiento con material del s. V d. C. en superficie. La presencia de materiales de construcción (fragmentos de tegulae y lateres) indica la existencia de estructuras, al mismo tiempo que los de dolia señalan actividades productivas ${ }^{4}$.

3. No hemos podido consultar el informe ni la memoria de estos sondeos.

4. Para estos yacimientos, véase Espinosa, 1996a y Frías, 2010.
- Foietes Dalt I: Dispersión de materiales de amplia cronología, entre los siglos II a. C. y VI d. C., entre los que destaca un ladrillo circular que podría pertenecer a un hypocaustum y otros materiales que podrían proceder de la vecina La Campaneta. En este mismo lugar se localiza una alquería islámica.

- Casa o Mas de l'Almiserà: En esta finca se localizaba la inscripción a la que dedicaremos el siguiente apartado. Además, las prospecciones llevadas a cabo en esta zona localizaron materiales cerámicos de época altoimperial y del s. VI (entre los que destacan fragmentos de arcilla vitrificada que podrían relacionarse con un horno) y un tramo de canalización de agua de mortero hidráulico.

- Camí la Vila II: Villa romana altoimperial. Restos de baños y otros materiales relacionados con una residencia señorial. Situada junto al camino romano por el que hoy discurre la CV-759. Probablemente, por estar en una zona llana, el estado de conservación es bueno. En 1806 se encontró en las proximidades una inscripción funeraria de la que hablaremos más adelante.

- Torres-Secanet: Villa altoimperial ubicada en la partida de El Serrano y prospectada entre 1991 y 1992. Es un hábitat de ciertas dimensiones (en torno a 0,5 ha), dotado de muros de considerable grosor (entre 40 y $65 \mathrm{~cm}$ ), de mampostería trabada con mortero y, en un caso, de opus quadratum. Es muy posible que se trate de un asentamiento agrícola. Tras una fase de época republicana, mal conocida, el grueso de los materiales nos lleva a los dos primeros siglos de la Era y, al menos, comienzos del siguiente, período al que deben pertenecer las estructuras documentadas.

- Torres Nord: materiales en superficie del s. I d. C., quizá en relación con la gran balsa hidráulica romana de época augustea de la partida de Torres (Olcina, 1990).

- Torres IV: asentamiento rural altoimperial.

De todos ellos, La Campaneta es, según nuestros actuales conocimientos, el yacimiento más destacado por su larga cronología, la existencia de grandes sillares, la gran potencia estratigráfica y, como veremos después, la probable existencia de una necrópolis. Ello lo convierte en el mejor candidato para un hipotético vicus en la zona.

\section{LA EPIGRAFÍA MAYOR}

En el entorno de l'Almiserà se conocen dos inscripciones (CIL II 3576 y AE 1989: 476). Desde finales del siglo XVIII, momento en el cual la arqueología empezaba a dar sus primeros pasos, han sido numerosos los investigadores que han realizado referencias a la primera de ellas. Se encontraba incrustada en la fachada de la finca de la casa o Mas de l'Almiserà, que 


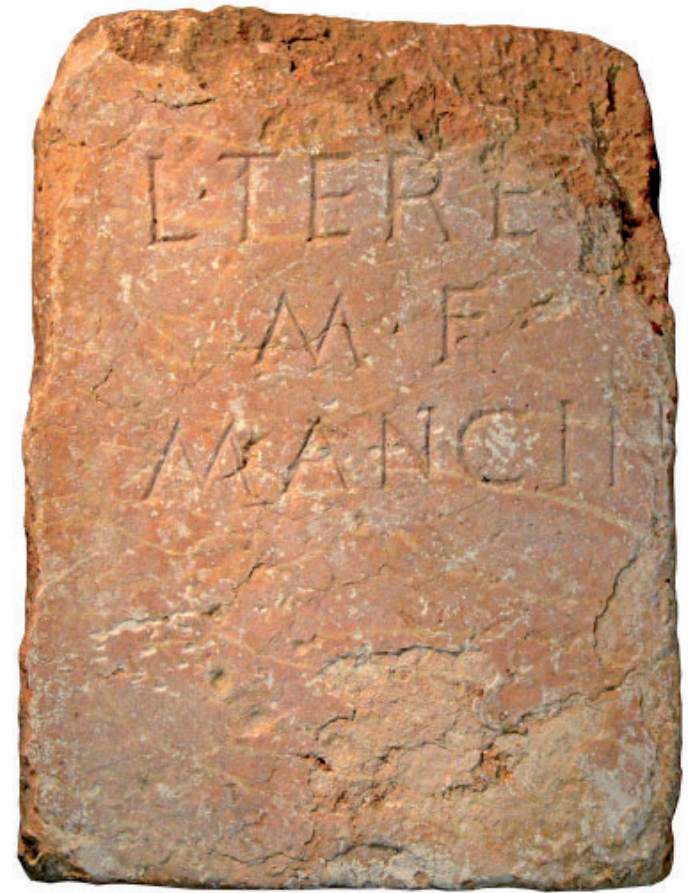

Figura 4: La inscripción del Mas de l'Almiserà.

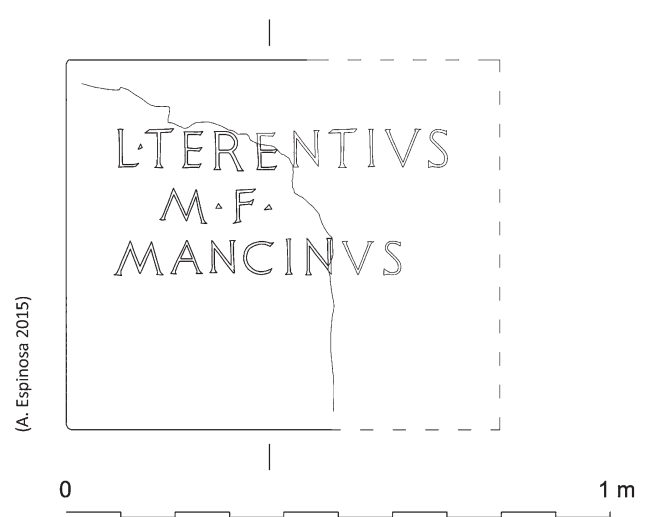

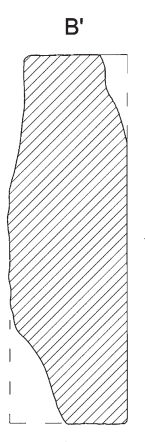

B

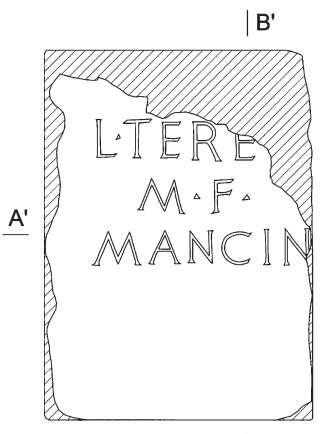

|B

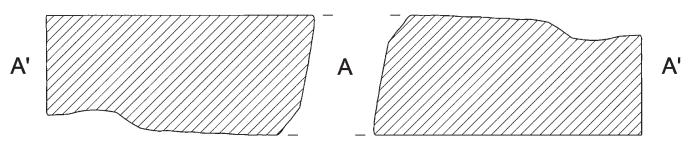

Figura 5: Calco de la inscripción del Mas de l'Almiserà, con propuesta de restitución de la parte que falta. históricamente ha pertenecido a la familia Aragonés. Fue recuperada recientemente por Vilamuseu (Red de Museos y Monumentos de Villajoyosa), donde se encuentra depositada desde entonces.

Se trata de una inscripción sobre un bloque de caliza de Buixcarró de $68 \times(49,5) \times 22 \mathrm{~cm}$ de fondo máximo, que se puede datar en el s. II según Manuel A. Rabanal y Juan Manuel Abascal $(1985,219$; véase también Abad y Abascal, 1991, 120, n 66). Rosario Cebrián $(2000,309$, ver C109) también la data en época Antonina, en cambio Josep Corell la lleva a comienzos del s. I d. C. $\left(1999,189-190, \mathrm{n}^{\circ} 109\right)$.

El campo inscrito ocupa $27 \times 40 \mathrm{~cm}$ y la altura de las letras es de $7 \mathrm{~cm}$ en la primera línea y $6 \mathrm{~cm}$ en las restantes. El tipo de monumento es más propio de una inscripción honorífica; sin embargo, la presencia de nombres que deben ir en nominativo permite deducir que es funeraria, en opinión de Juan Manuel Abascal. Josep Corell también la cataloga como tal. Publicamos aquí su primera fotografía tras la recuperación y limpieza (Fig. 4) y un calco inédito (Fig. 5).

Tenemos un fragmento inferior izquierdo, en el que se puede leer L(ucius) · Tere [ntius] / M(arci) $f($ ilius) . / Mancin[us?], es decir «Lucio Terencio Mancin(o?), hijo de Marco (...). Se ha perdido, evidentemente, la tribu después de la filiación.

La referencia más antigua a esta pieza es de Francisco Pérez Bayer (Pérez Bayer, 1998), que el 25 de abril de 1782 se desplazó a Villajoyosa para documentar epígrafes antiguos:

En la heredad llamada Almiserà, que es hoy del doctor Jaime Aragonés ${ }^{5}$ y dista una hora de camino de Villajoyosa hacia el norte, y como media hora del lugar de Finestrat, vi y copié la inscripción siguiente:

\section{TEREN////}

M. F. MANCIN////

Por tanto, la pieza ha permanecido en ese mismo lugar desde entonces.

Otra inscripción procedente de la zona se descubrió en 1806 en una casa de campo de la partida de l'Alfarella ${ }^{6}$, donde la dibujó dos años después Bartolomé Ribelles (Abad y Abascal, 1991, 123-124), aunque hoy está desaparecida. Es del s. I d. C. y dice: Saenia Abra hic sita (e)st («Aquí yace Senia Abra»). La casa se encontraba junto al antiguo camino de Villajoyosa a Finestrat, en las proximidades de la villa de Camí la Vila, con la que quizá guardase relación; pero la de l'Almiserà debía estar desplazada de su ubicación

5. Probablemente se refiera a Jaime Aragonés Pellicer (16981769), según el árbol genealógico de la familia Aragonés confeccionado por $\mathrm{M}^{\mathrm{a}}$ Jesús Marí y Carmina Bonmatí, de Vilamuseu.

6. La partida Alfarelles o Alfarella se encuentra en el límite del término municipal de Finestrat con el de Villajoyosa. 
original, porque no hay un yacimiento altoimperial destacado bajo esta antigua masía, en cuyos muros se reaprovechó la pieza en época moderna.

La inscripción de l'Alfarella podría relacionarse con una necrópolis asociada a una calzada que condujese al valle de Finestrat, pero la de l'Almiserà abre unas interesantes expectativas que comentaremos más adelante.

\section{EL YACIMIENTO DE LA CAMPANETA EN LAS FUENTES}

Las fuentes del siglo XIX nos confirman la existencia de una necrópolis romana en la partida de l'Almiserà y aportan datos interesantes sobre villas romanas de la zona. La referencia más antigua es de Juan Agustín Ceán Bermúdez $(1832,125)$, que habla de un yacimiento al norte de la Torre de Sant Josep:

\begin{abstract}
Aun hubo de extenderse mas esta antigua población ácia el norte, pues se encuentran por allí las mismas ruinas, grandes piedras escodadas, otro ramal de acueducto con arcaduces muy gruesos de barro, un buen trozo de un pavimento mosaico compuesto de piedrecitas azuladas, verdes, blancas y rojas, formando agradables figuras; y junto á este otro pavimento de ladrillos cortados y bien unidos, cada uno de 2 pulgadas y 3 líneas de grueso con la marca siguiente de la oficina; OF. LVC. Seguía en el lado opuesto otro pavimento teselato con losetas de alabastro y de jaspes de varios colores, y un gran pedazo de mosaico blanco y aplomado, mas tosco que los anteriores. Se descubrieron también por este lado septentrional otros sepulcros con esqueletos dentro, lucernas, una ánfora de barro saguntino, y muchas medallas de Marco Aurelio, de Alejandro Severo, y de Marco Julio Philippo.
\end{abstract}

Cuando dice que «aún hubo de extenderse más esta antigua población» lo hace influido por el Conde de Lumiares (Valcárcel, 1852), que a su vez se basa en Gaspar Escolano (1610-1611, libro 6 ${ }^{\circ}$, capítulo XII), quien pensaba que la ciudad romana se localizaba en los alrededores de la Torre de Sant Josep; pero ninguno de los restos que describe se conservan o corresponden a yacimiento alguno actualmente visible en el curso medio o alto del río Torres, donde se ubica la partida de l'Almiserà. No obstante, las referencias a tumbas quizá puedan relacionarse con la siguiente noticia, publicada en el periódico El Español el 29 de noviembre de 1846 :

En el partido llamado de Almiserà, cerca de la misma población, trabajando una tierra un labrador se encontró una piedra labrada en forma de caja, de construcción tosca y sin ornamento alguno, la que contenía dentro, además de huesos humanos que se hacian polvo al tocarlos, varias monedas, de las cuales tenemos tres, una de ellas conservada intacta, teniendo por una parte un busto dibujo y grabado perfecto con la siguiente inscripción: ADRIANUS AVQ CONS YM y del otro una diosa armada de casco y lanza con las letras S.C. y el lema PROVIDE SAVG.

En este caso la mención a la partida de l'Almiserà es clara y concreta, y el texto parece aludir a un sarcófago que contendría una inhumación de época de Adriano o posterior.

Otro artículo de interés es el publicado en la revista El Archivo en julio de 1889 (Chabás, 1889, 261). Extractamos de él los fragmentos que resultan interesantes para nuestro objeto de estudio:

\begin{abstract}
Subsisten aun en Villajoyosa notables restos de la antigüedad romana que merecen estudio á parte, y Dios mediante lo haremos. En una heredad de D. Cayetano Aragonés ${ }^{7}$, en el altozanito que se levanta detrás de la casa, se encuentran con profusión restos romanos. Sembrados están aquellos campos de cerámica de aquella edad, muchos fragmentos de todas las variedades del barro saguntino, tessellae de mosaico coloradas, verdes, negras y blancas, de todas estas clases vimos en un momento que alli estuvimos, y con posterioridad se ha destruido un mosaico entero que salió al roturar aquellos campos. Pedazos de mármol, monedas romanas y celtiberas, además de los restos arquitectónicos que cubre la tierra y al parecer son restos de murallas, acueductos subterráneos, etc.
\end{abstract}

Por la descripción de los materiales encontrados y por mencionar un cerro podemos pensar que el autor está aludiendo a la villa de Xauxelles (Belda, 1946; Belda, 1947; Belda, 1948; Espinosa, 1990), ya que esta finca también fue propiedad de la familia Aragonés, como tantas otras en Villajoyosa. No creemos que se refiera a La Campaneta, porque en este caso el yacimiento no está detrás sino debajo y alrededor de la casa, y allí no existe un cerro sino más bien un talud en el glacis de la llanura litoral. Hemos de descartar la villa de la Jovada (Belda, 1953; Espinosa, 1996b; Ruíz y Marcos, 2005) ${ }^{8}$, situada junto a la finca La Barbera dels Aragonés, hoy en el casco urbano de Villajoyosa, ya que, aunque la casa fue también propiedad de esta familia, no existe un cerro en las proximidades.

En otro fragmento del mismo escrito, Roque Chabás vuelve a hacer mención de un yacimiento supuestamente localizado en l'Almiserà:

Y ya que de las antigüedades de Villajoyosa hablamos, vamos á copiar lo que teníamos preparado para nuestra miscelánea. En el término de esta villa

7. Se puede referir a Cayetano Aragonés Aragonés (1854-1895) o a Cayetano Aragonés Aragonés (1866-1935) según el árbol genealógico de la familia Aragonés confeccionado por $\mathrm{M}^{\mathrm{a}}$ Jesús Marí y Carmina Bonmatí, de Vilamuseu.

8. J. Belda la llamó «villa de la Encina», por un gran árbol de esta especie que hay en los jardines de La Barbera (Belda, 1953). 
se han descubierto poco hà preciosos restos de la antigüedad romana. Ya en febrero tuvimos el gusto de explorar una colinita donde D. Cayetano Aragonés ha edificado una casa de campo, camino de Finestrat y en ella descubrimos restos de edificaciones y mucho detritus de barro saguntino y tessellae de mosaico de varios colores, azules de vidriado y coloradas de barro cocido durísimo. Entre las tierras, que cubren los acueductos y cimientos, vimos también restos pequeños de mármol. Según avisa nuestro querido amigo el entusiasta é inteligente anticuario de dicha población D. Francisco Martínez Esquerdo, hace poco que, trabajando en sacar piedra de dicho montecillo, se descubrió un piso de mosaico que fue destruido, pues cuando tuvo noticia de ello ya no pudo rescatar de la profanación mas que un trozo de la cenefa que lo rodeaba. Solo se ha podido, pues, conservar un pedazo de un metro de largo por setenta centímetros de ancho. Las piedrecitas (tessellae) del mosaico en la parte que queda son blancas, negras y encarnadas. También se encontraron, y conserva nuestro amigo, un trozo extraído de columna de mármol. ¿Qué sería aquella colinita en tiempos de romanos? Acaso trabajando en los alrededores se podría calcular con datos fijos la situación en su falda de alguna población; pero circunscritos los restos á solo la colina, que es pequeña, no cabe conjeturar en ella mas que la existencia de alguna rica villa ó casa de campo de algún personaje romano.

Otro día nos ocuparemos de las cuestiones geográficas á que dan lugar los descubrimientos de Villajoyosa, importantes bajo todos conceptos (Chabás, 1889, 262).

En esta ocasión parecería inequívoco que el autor se refiere a la masía de l'Almiserà, por el propietario y, sobre todo, por la mención al camino de Finestrat, ya que Xauxelles está junto al camino real de Orcheta, no el de aquella otra población. Sin embargo, hay que tener en cuenta dos cosas: en primer lugar, que el camino de Orcheta enlazaba $2 \mathrm{~km}$ al norte de Xauxelles con el camino viejo de Alicante a Finestrat, que discurría entre la Sierra de Orcheta y l'Alt de l'Olivoner; $y$, en segundo lugar, que sabemos que fue Francisco María Martínez Esquerdo quien comenzó a interesarse por la villa monumental de Xauxelles (de hecho, podemos considerarlo su descubridor); y que los restos que se describen en el texto, así como la mención de una «colinita», nos llevan con toda probabilidad a este yacimiento y no al de l'Almiserà'.

Un año después Chabás (1890a, 72) vuelve a mencionar en la revista El Archivo el mosaico extraído por Francisco $\mathrm{M}^{\mathrm{a}}$ Martínez Esquerdo: «En Villajoyosa

9. También hemos valorado el hecho de que una inscripción del umbral de la casa de l'Almiserà aportaba la fecha de 1901 para una reforma, y por tanto la expresión «ha edificado una casa de campo» podría indicar una primera fase de las obras doce años antes, en 1889, cuando se estaba extrayendo piedra «de dicho montecillo» (¿para las obras?). No obstante, este argumento tiene poco peso y se podría aplicar a cualquiera de los dos lugares, Xauxelles y l'Almiserà. también se ha descubierto otro mosaico, que se ha trasladado a la Villa y va a ser restaurado. Sus colores son: negro, colorado y dos matices de blanco».

Dos meses después, el mismo autor (Chabás, 1890b, 117-118) menciona otro mosaico de Villajoyosa, comparándolo con otro descrito en El Puig (Valencia) por Antonio de Valcárcel:

Los mosaicos de Villajoyosa. - Van adquiriendo más y más importancia estos venerados restos, cuanto más en su estudio entramos. En el siglo pasado se descubrieron otros en el Puig, que tuvieron la suerte de ser descritos y dibujados por el Príncipe Pío, quien remitió su trabajo a la Academia de la Historia en 1805. Afortunadamente esta corporación los publicó en 1852 en el tomo VII de sus Memorias.

Los mosaicos de Villajoyosa y los del Puig son seguramente de la misma época y sus dibujos nos revelan el arte cristiano primitivo. No diremos que sean anteriores a Constantino, pero no deben ser muy posteriores a este emperador. Que sean de la misma época no cabe duda, pues los dibujos de las láminas 40 y 42, son iguales a los que hemos visto en el tosal de Aragonés; el pez y la paloma de la lámina 44 son característicos del arte cristiano, lo mismo que el tema de la gamma, tan frecuente en los monumentos de las catacumbas, y que tanto en el Puig como en Villajoyosa, pero más en los mosaicos de la primera, aparece, no como tema casual de dibujo, sino como simbolos para expresar una idea religiosa. Hay, pues, que estudiar estos preciosos restos para depurar nuestro génesis cristiano tan poco y mal estudiado hasta ahora.

En este pasaje se dice que los mosaicos de El Puig y los del tossal de Aragonés son muy similares. Al observar los dibujos del mosaico de El Puig es clara la similitud con los de Xauxelles, lo que constituye otro argumento para identificarlos con los de esta villa y descartar l'Almiserà ${ }^{10}$ o más bien, dentro de esta partida, La Campaneta: la falta de evidencias materiales romanas debajo de la casa de los Aragonés en l'Almiserà, a pesar de ser un terreno bien prospectado, hace improbable, como hemos anticipado más arriba, la existencia de una villa entera dotada de mosaicos.

En cuanto al mosaico y la columna que menciona, no han llegado hasta nosotros, a pesar del interés del anticuario e historiador Francisco Martínez Esquerdo, cuya Historia de Villajoyosa lamentablemente no se ha conservado o al menos no se ha podido localizar, ya que de seguro habría ofrecido más detalles sobre este particular.

Una mención en una obra de Teodoro Llorente $(1889,864)$ se refiere sin duda a Xauxelles:

Entre los muchos restos de antigüedades encontrados en los alrededores de Villajoyosa, debe

10. Ver Espinosa, 1990 y Arasa, 2011, con bibliografía anterior en ambos casos. 
mencionarse un mosaico, bien conservado bajo la capa de tierra que lo cubría, en la finca de D. Pedro Aragonés, a la izquierda del camino de Villajoyosa a Relleu y Sella, a unos cuatro kilómetros de la villa. Sacó de él copia fotográfica el director de la Escuela de Bellas Artes de Barcelona D. Leopoldo Soler y Pérez.

No obstante, la distancia de $4 \mathrm{~km}$ a Villajoyosa es exagerada, y cuadraría más con La Campaneta o l'Almiserà que con Xauxelles (en este caso es de unos 2,5 km). Quizá los yacimientos de La Campaneta y Xauxelles se descubrieran por las mismas fechas en fincas ambas propiedad de los Aragonés, y de ahí las confusiones y datos cruzados. Por lo que parece, las menciones a mosaicos se refieren a los de Xauxelles, pero parece claro que la partida de l'Almiserà, en la que se encuentra la finca de La Campaneta, también proporcionó interesantes hallazgos desde antiguo.

\section{EL MONUMENTO DE L'ALMISER À}

Más allá de las ambiguas noticias que hemos citado, la existencia de restos monumentales está documentada en la finca de La Campaneta y su entorno. Por una parte se conocen desde hace tiempo algunos sillares moldurados que analizaremos a continuación; por otra parte, tenemos el gran sillar localizado durante los sondeos para un gasoducto, que hemos mencionado más arriba (Fig. 13) (pieza E).

El llamado «monumento romano de l'Almiserá» es uno de los restos más relevantes localizados en la zona de La Campaneta. La referencia más antigua a esta construcción la hemos encontrado en la obra Historia de Villajoyosa de Ignacio Martí Miquel (1877-1922, pág. manuscritas 786-787):

\begin{abstract}
Un insigne y erudito historiador valenciano autor de un libro titulado Valencia y que firma con pseudónimo "Valentino», hizo una excursión a Villajoyosa y nos refiere que, además de haber examinado detenidamente el monumento romano o sarcófago de San José, visitó con el entonces alcalde Don Antonio Lloret, en el año 1904, las ruinas que hay en un mas suyo, partida de Almiserà, y que indudablemente hubo alli un templo romano y otro edificio monumental de aquella edad, pues entre otros sillares se encuentran tres muy grandes bien moldurados, piezas sin duda de un cornisamiento; dista dicho punto de Villajoyosa cuatro kilómetros y medio.
\end{abstract}

Hasta el hallazgo de este manuscrito, estos sillares solo eran conocidos por noticias que hablaban de su cubrimiento por la autopista A-7 en los años 70 del siglo XX. Ahora sabemos que ya se conocían al menos desde 1904

El siguiente fragmento, extraído de la obra Catálogo monumental y artístico de la provincia de Alicante (1907-1908) de Manuel González Simancas (1907-1908 (2010), 137), hace referencias a la finca
La Campaneta, en la que se encuentra la Ermita de San Isidro:

Torre de San Isidro.- En la partida Almiserans, una pequeña eminencia, sobre la que se encuentran fragmentos de cerámica ruda, a mano, de vasijas grandes y también de barros saguntinos. Al pie de la eminencia se hallaron sepulturas, y arriba cimentaciones de antiguo edificio, quizá de la Edad Media y una casa de campo pequeña.

La torre es de planta cuadrada y quedan los canes (dos) de un pequeño matacán. Como esta torre hay varias en la huerta y en la partida citada y en la de Aixihuilis.

Lo que más destaca es la mención a la torre de San Isidro, monumento desconocido hasta la fecha. La demolición en el s. XX del tercer piso, que tuvo el matacán, ha causado que los otros dos conservados de esta torre de huerta permanezcan enmascarados dentro de la casa de La Campaneta. Por otra parte, la mención de tumbas a los pies del cerro puede guardar relación con las que recogen los textos que hemos analizado más arriba.

La siguiente referencia (González Simancas, $1907-$ 1908 (2010), 137-138), escrita a continuación de la anterior, nos aporta datos importantes sobre el monumento romano de l'Almiserà (de nuevo aparece Antonio Lloret como persona acompañante):

Finca Almiserans, cuatro sillares enormes de la misma piedra que la del monumento, con molduras como las de aquel, y también en tres de los costados. Propiedad a unos $5 \mathrm{~km}$ al $N$ de Villajoyosa. Hay un sillar suelto y debe haber más enterrados.

D. Antonio Lloret y Lloret (mi acompañante).

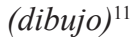

1 metro de lado y algo menos de frente. Son tres y un sillar con indicación de almo-(debajo: 0,45) hadillado como el basamento del gran sepulcro.

Este texto confirma que había a la vista tres sillares moldurados. Hoy conservamos dos, además del almohadillado.

De localizarse toda la necrópolis donde dice González Simancas, probablemente las obras de la autopista AP-7 la arrasaron o cubrieron en su mayor parte o incluso en su totalidad. En cambio, si existen tramos de este cementerio al norte u oeste de la finca, quizás se conserve algo, puesto que al observar una fotografía aérea de la zona tomada en julio de 1976 (Fig. 7), en plenas obras de la autopista y del Área de Servicio La Marina, se comprueba que esas son las únicas zonas cuyas tierras no fueron removidas.

Las fotografías anteriores a estos movimientos dejan ver claramente un camino antiguo que discurre al oeste de la casa, de norte a sur, hacia Villajoyosa (Fig. 8). Es probable que fosilice el camino

11. Lo reproducimos en la figura 6. 


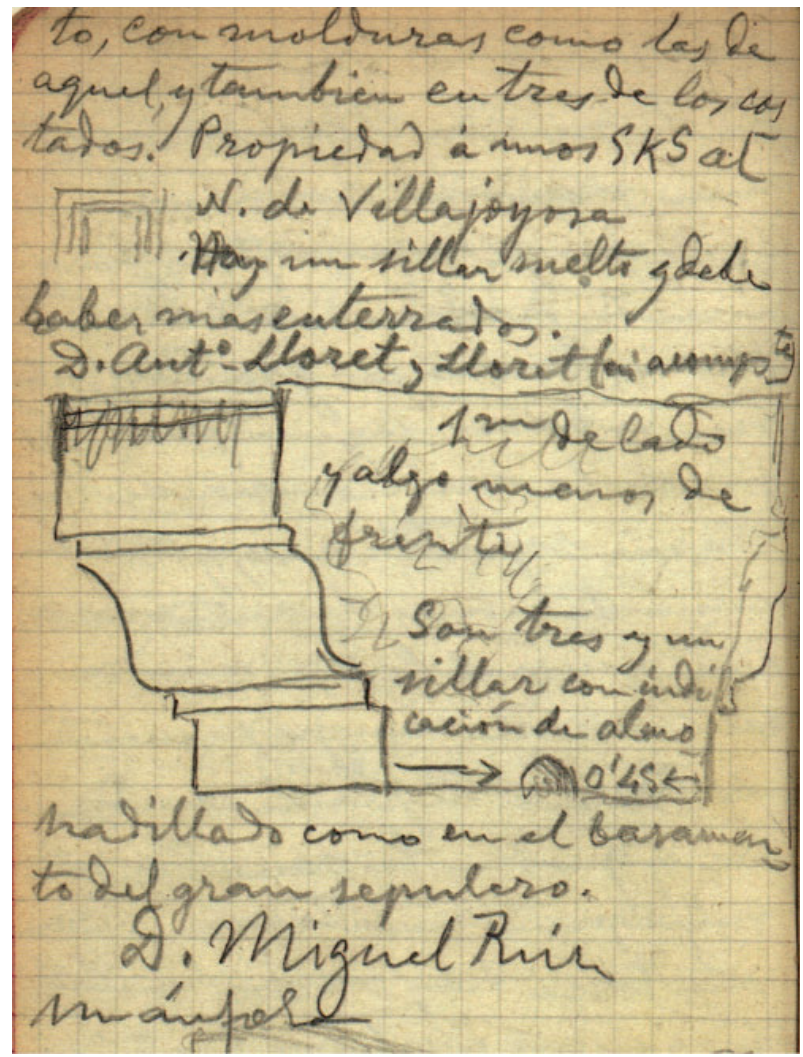

Figura 6: Croquis de los sillares de l'Almiserà según González Simancas (1907-1908 (2010), 138).

romano y que a sus lados se ubicase la necrópolis que buscamos.

En entrevistas con familiares de los propietarios de La Campaneta se nos ha informado que a consecuencia de estas obras se descubrieron algunos de los sillares que hoy conservamos en el parque del Centre Social Llar del Pensionista; en este caso, los bloques mencionados en los textos seguirían enterrados en las inmediaciones o bajo el terraplén de la autopis$\mathrm{ta}^{12}$. No obstante, la concordancia de las molduras con las dibujadas por González Simancas y el hecho de que se conserven dos sillares moldurados y uno almohadillado, como dicen los textos, confirman que en realidad las piezas que han llegado hasta nosotros son tres de las referidas por aquellos autores, y no otras.

Durante las obras de la AP-7, afortunadamente, dos de los sillares moldurados y el almohadillado se trasladaron a una casa de campo en la partida de La Cala (Fig. 9). En mayo de 1997, cuando la finca se

12. Gracias al trabajo de fin de licenciatura de Vicente Sebastià (2013, anejo II, Evolución histórica de la playa: pág. 6) sabemos que los escombros de la obra de la autopista AP-7 fueron depositados en la playa de Puntes del Moro con el objetivo de crear una barrera artificial y ganar terreno al mar. De hecho, se han recibido ocasionalmente en Vilamuseu noticias de objetos romanos en estos rellenos.

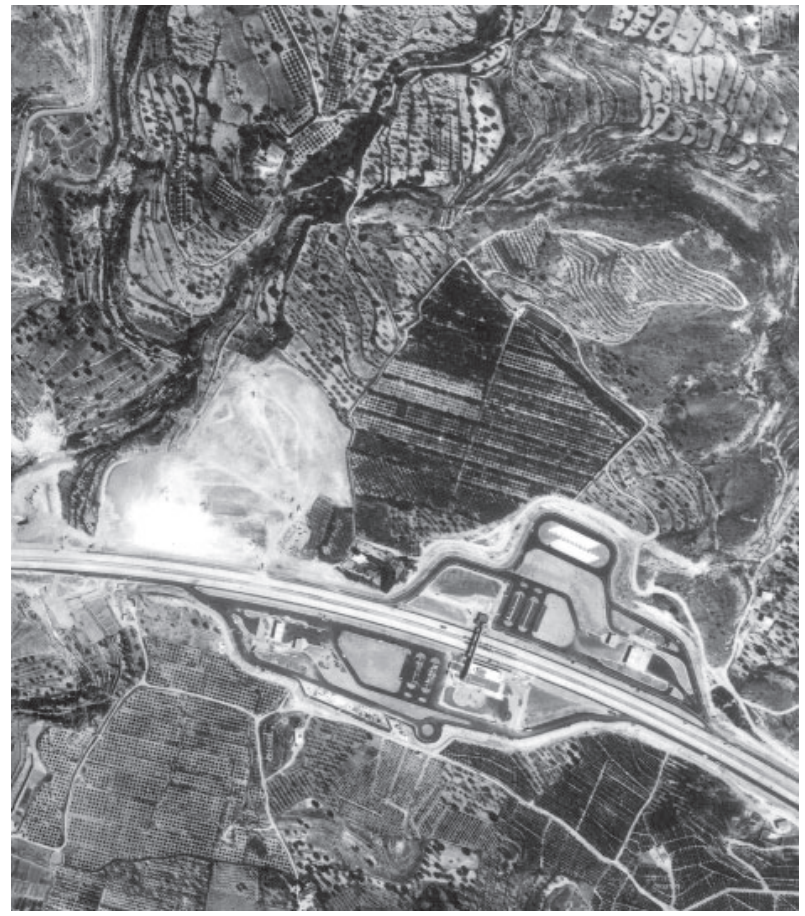

Figura 7: Las obras de la autopista A-7 en julio de 1976 (Archivo Histórico Municipal de Villajoyosa).

encontraba en proceso de venta, el nuevo comprador, Josep Márquez, comentó al Museo la existencia de unos sillares que podrían tener interés arqueológico. Márquez pidió a la propietaria que donara las piezas al Museo Municipal en caso de confirmarse su antigüedad. En la visita del director del Museo Municipal, Antonio Espinosa, se comprobó que los sillares eran de época romana y el 22 de mayo los vendedores de la finca, Jaume López Lloret y Magdalena Zaragoza Lloret, los donaron al Ayuntamiento. Hoy se exhiben en los jardines del Centro Social de la calle Huit de Maig, donde se restauraron in situ y se instalaron en sentido inverso al que se encontraban en la finca de La Cala, ya que se comprobó que existían orificios en forma de cola de milano que determinaban la cara superior.

El 30 de septiembre de 1999 ingresó en los fondos del Museo Municipal un nuevo sillar rectangular de caliza procedente de la finca La Campaneta (pieza D).

Hemos identificado los sillares que se encontraban en la finca de La Cala en 1997 como piezas A, B y C; el sillar procedente de La Campaneta como pieza D; y el hallado en los sondeos para el gasoducto con la letra E.

La piedra del monumento de l'Almiserà es idéntica a la de la Torre de Sant Josep y a la de los sillares de las termas monumentales de la calle Canalejas, y procede de la zona de Cales i Atalaies, en el extremo este del término municipal de Villajoyosa, donde en 1991 se descubrió una cantera altoimperial, documentada en 2012 por Diego Ruiz y Ana Charquero. Se trata de una caliza dolomítica dura que, según información de $\mathrm{M}^{\mathrm{a}}$ 


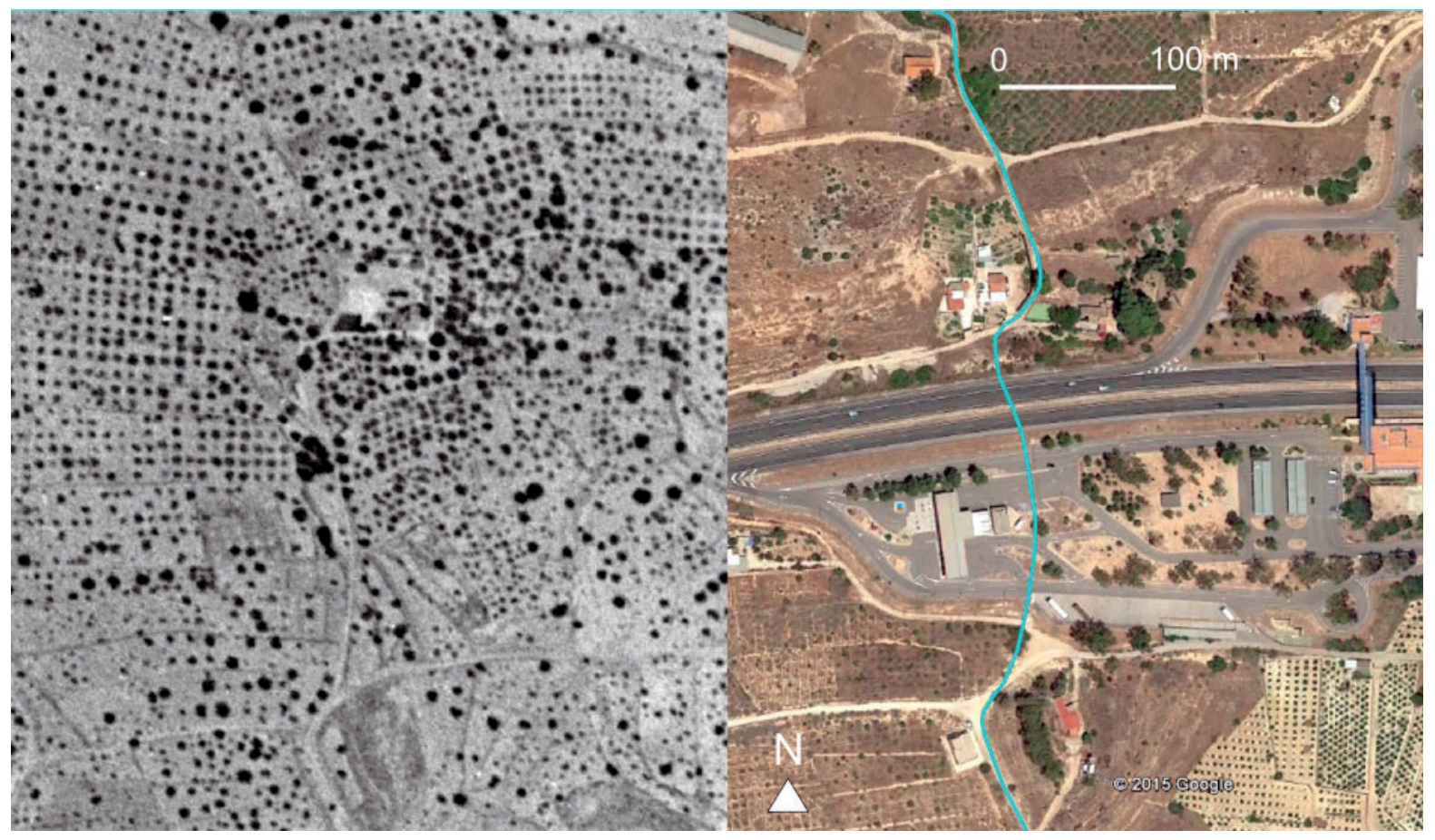

Figura 8: A la izquierda, fotografía aérea de 1945 (Terr@sit, vuelo VF 1945, fotograma 020, pasada 020). A la derecha, imagen actual con el camino antiguo marcado. A la derecha del camino antiguo y al lado norte de la autopista, en el centro de la imagen, la casa de La Campaneta.

Ángeles García del Cura, es característica de esa zona de la provincia de Alicante ${ }^{13}$.

\section{DESCRIPCIÓN DE LOS SILLARES}

A (Fig. 10): extremo del zócalo o basamento de un pedestal de forma rectangular. Se asienta sobre un plinto de paredes verticales y se encuentra rodeado, entre anillos, de una moldura de cyma recta en tres de sus caras. En el mismo bloque se aprecia la tendencia vertical del monumento, puesto que contiene el comienzo del dado. En el centro de gravedad posee una cavidad vertical para su suspensión y montaje mediante castañuelas, y en el centro del extremo del lado sin moldurar una horizontal para el ensamblaje de los sillares mediante colas de milano (Adam, 2002, 51-56). Las medidas máximas son: longitud $111 \mathrm{~cm}(3,75$ pedes $=3$ pedes y 3 palmi $/ 12$ digiti/9 unciae), anchura $90 \mathrm{~cm}(3$ pedes $)$, altura $57 \mathrm{~cm}(1,9$ pedes $=1$ pes y 15 digiti 11 unciae). El dado mide 54,6 cm de ancho, 15,08 cm de alto $(1 / 2$ pes $=2$ palmi $/ 8$ digiti $/ 6$ unciae $)$ y $92,82 \mathrm{~cm}$ de longitud ( 3 pies y 2 digiti) (las dos últimas medidas son parciales porque el pedestal estaba formado por otra pieza). La metrología altoimperial romana estándar, aunque no en cifras redondas, parece aplicable a esta pieza.

13. La distancia entre la Torre de Sant Josep y la cantera es de $1,7 \mathrm{~km}$ en línea recta, $2,8 \mathrm{~km}$ por el supuesto trazado del camino costero romano.
B (Fig. 11): de similares características y dimensiones que el anterior, salvo la longitud $(86 \mathrm{~cm}=2,9$ pedes $=2$ pedes y 11 unciae $)$ y la altura $(51 \mathrm{~cm}=1$ pie $\mathrm{y}$ 3 palmi/12 digiti/9 unciae). Se encuentra muy erosionado en una de sus caras.

C (Fig. 12: sillar rectangular con restos de almohadillado. Está bastante deteriorado. No posee orificios para suspensión o ensamblaje. Las medidas máximas son: longitud $88 \mathrm{~cm}$ (3 pedes); anchura $46 \mathrm{~cm}$ (1,5 pedes $=1$ pes y 2 palmi $/ 8$ digiti/6 unciae); altura $62 \mathrm{~cm}$ (2,1 pies).

D (Fig. 12): sillar rectangular con probables restos de almohadillado. Está muy dañado. Las medidas máximas son: longitud $108,5 \mathrm{~cm}$; anchura $33-40 \mathrm{~cm}$; altura $32,5 \mathrm{~cm}$.

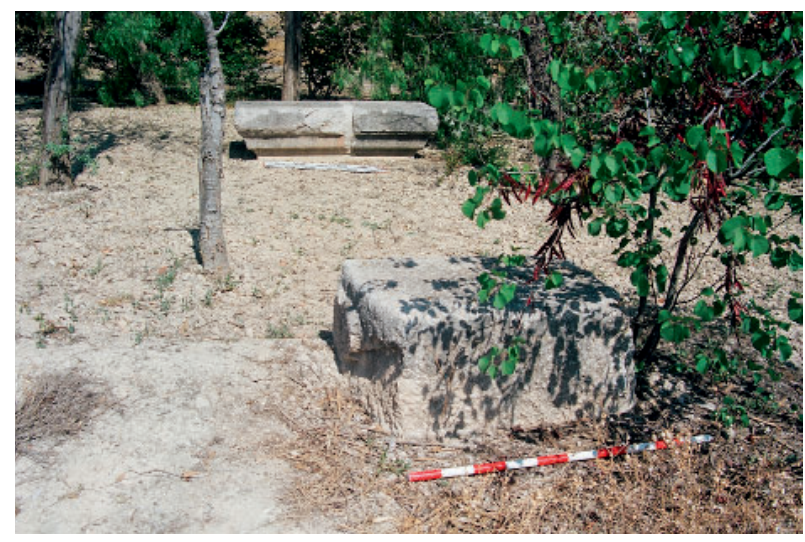

Figura 9: Los sillares conservados en la finca de La Cala (fotografía de Antonio Espinosa). 

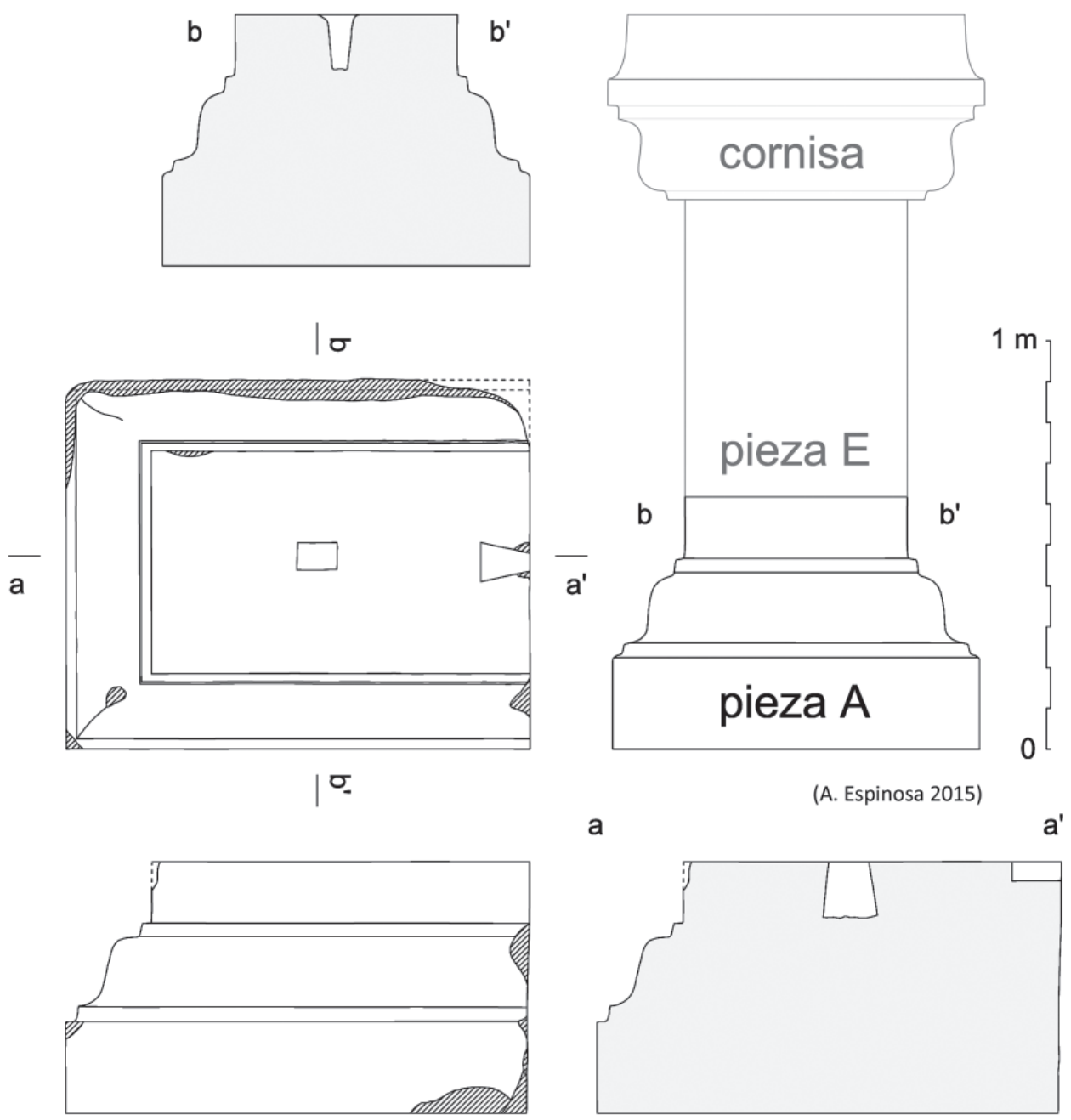

Figura 10: Sillar A y su composición con el sillar E y las cornisas del entorno de la Torre de Sant Josep.

E (Fig. 13): sillar rectangular de grandes dimensiones, con cavidad para las castañuelas en su centro de gravedad. Dimensiones: longitud $172 \mathrm{~cm}$ (5 pedes y 3 palmi/12 digiti/9 unciae); anchura $54,5 \mathrm{~cm}$ (1 pes y 10 unciae); altura $73 \mathrm{~cm}(2,5$ pedes $=2$ pedes y 2 palmi $/ 8$ digiti/6 unciae). Es la única pieza del conjunto que se conserva en los jardines del parque municipal de Barberes Sur, en Villajoyosa.

El perfil de los sillares A y B y sus dimensiones son idénticos, salvo por su altura (Fig. 14), ya que B es 6 $\mathrm{cm}$ (tres digiti) más bajo que A. Por tanto, la muesca para la cola de milano no encaja y estamos ante piezas de monumentos diferentes o, menos probablemente, ante partes diferentes del mismo monumento.

Al estudiar el monumento de l'Almiserà nos encontramos con el problema de que solo tenemos piezas del zócalo. No obstante, por los paralelos, deben pertenecer a pedestales; y por su ubicación lejos del foro de Allon, probablemente sean funerarios, pertenecientes a alguna necrópolis del territorium. Cuando acometimos el estudio de estas piezas propusimos su pertenencia a la necrópolis rural de la que habla González Simancas, que él sitúa «al pie de la eminencia» de La Campaneta, lo que equivale a decir al sur, es decir, debajo del trazado de la autopista (Fig. 8); pero la búsqueda de los paralelos más próximos nos ha llevado a otra hipótesis que creemos tiene visos de ser la correcta, y que pasamos a argumentar.

La planta del basamento de la conocida torre funeraria de Sant Josep, de Villajoyosa, está rodeada de una moldura de cyma recta que se ajusta a los entrantes y salientes de las pilastras, y que es prácticamente idéntica a las del monumento de l'Almiserà. Una pieza anepigráfica conservada en el entorno de la torre tiene igualmente arriba y abajo sendas molduras de cyma recta aunque poco pronunciadas; la inferior apoya sobre plinto liso y la superior remata en un cuerpo de paredes ligeramente oblicuas (Abad y Bendala, 1985, 157-161): por sus dimensiones $(145 \times 77 \times 54 \mathrm{~cm})$ y por la superficie superior plana con orificio de castañuela, $\sin$ foculus, se trata de un pedestal del tipo que Rosario Cebrián $(2000,100)$ denomina «mololítico con base y coronamiento» y no de un ara (ver Ruiz y Charquero, 2014) (Fig. 14).

Pero el paralelo más claro para las piezas de l'Almiserà son otras cuatro fragmentadas que se conservan junto a la mencionada torre y que tampoco pertenecen a ella, sino a su entorno monumental, en 

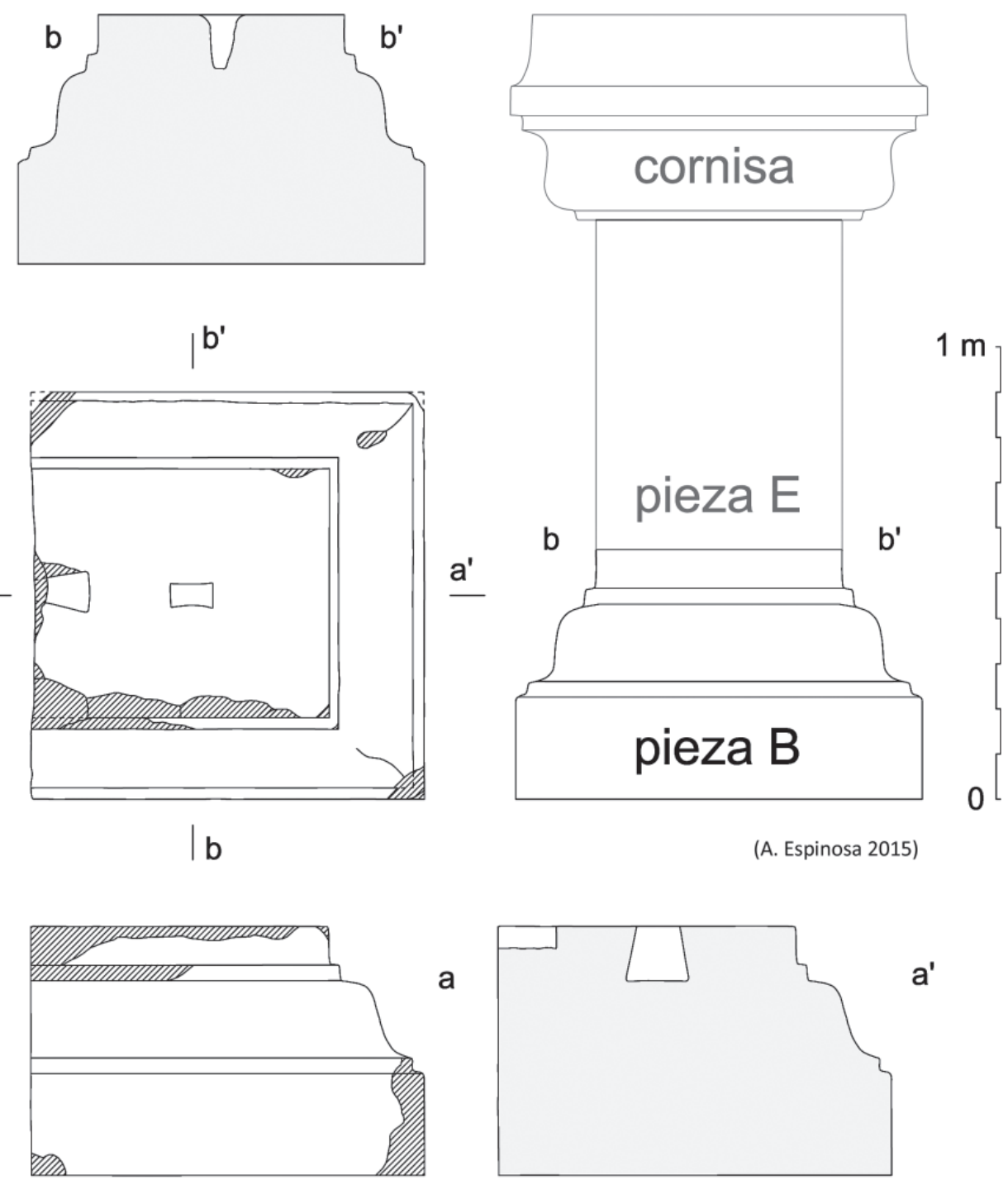

Figura 11: Sillar B y su composición con el sillar E y las cornisas del entorno de la Torre de Sant Josep.

el interior del recinto funerario (Fig. 16). Poseen una amplia cyma reversa de perfil con curvas muy pronunciadas, entre anillos, rematada por un cuerpo de lados oblicuos (Abad y Bendala, 1985, 160; Ruiz y Charquero, 2014, 172-173). Según Diego Ruiz y Ana Charquero, estas piezas podrían formar parte de la cornisa de uno o mejor dos pedestales funerarios, a juzgar por la excesiva longitud que tendrían en el primer caso. Dos de las piezas presentan orificios ovalados que podrían estar destinados al anclaje de esculturas. La forma alargada de los pedestales que nos ocupan sugiere que estuviesen destinados a soportar parejas escultóricas o estatuas ecuestres.

Los pedestales son, generalmente, soportes de estatua, en su mayor parte de carácter honorífico, aunque también los hay con función funeraria. Su estructura se compone normalmente de: un basamento o zócalo; un elemento central (dado) donde se suele situar una inscripción; y un coronamiento en cornisa, normalmente moldurada en forma de $\mathrm{S}$ (cimacio). Sobre la cornisa, en ocasiones, encontramos un plinto con los anclajes para la colocación de la estatua (Cebrián, 2000, 100). Esta es exactamente la estructura de los pedestales que nos ocupan. Las piezas de l'Almiserà pertenecen, pues, a dos (mejor que a uno) monumentos de la misma tipología que aquellos a los que pertenecen las cuatro piezas de la Torre de Sant Josep, probablemente similares al pedestal de los Calventii hallado en el foro de Segóbriga (Abascal, Alfödy y Cebrián, 2011, 78). Estos pedestales funerarios podían ser copias o duplicados de otros ubicados en espacios públicos urbanos (Ruiz Osuna, 2009, 115; Ruiz y Charquero, 2014) $)^{14}$.

Otra opción tipológica es la que presentan algunos monumentos como el de los Rabiri, el de Ilaro Fusco o el del Frontespizio en la Vía Apia (Fejfer, 2008, 117), en forma de altar con retratos de los fallecidos, y culminados por un tímpano. El fenómeno de los altares

14. Remitimos al artículo de Diego Ruiz y Ana $\mathrm{M}^{\mathrm{a}}$ Charquero en esta misma revista sobre otros paralelos hispanos. 


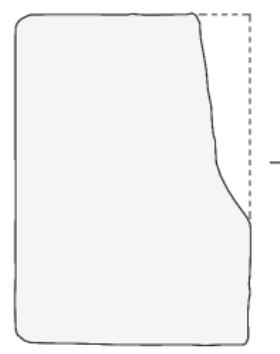

$a^{\prime}$

pieza C la

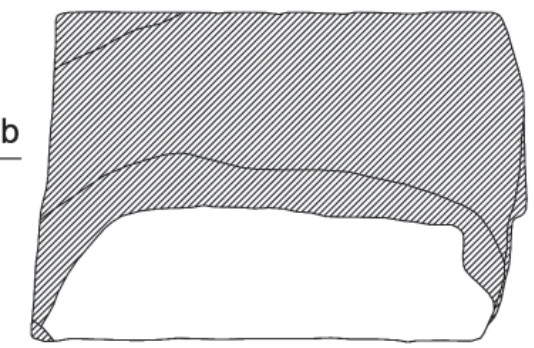

$\mid \mathbf{a}^{\prime}$
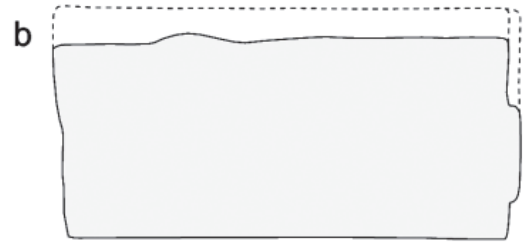

$70 \mathrm{~cm}$
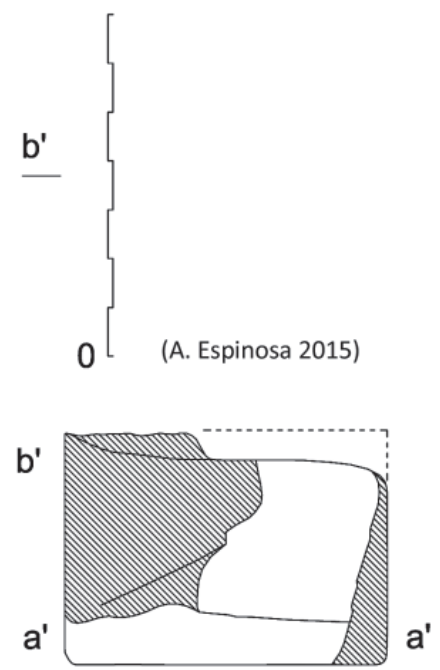

\section{pieza $\mathrm{D}$}
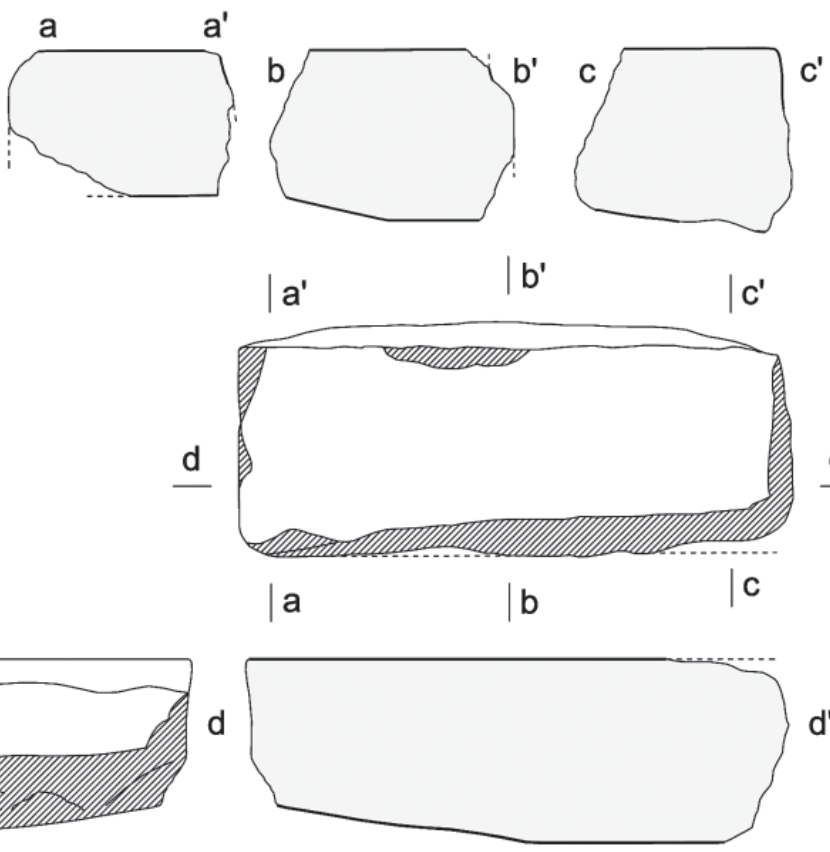

$\mid c^{\prime}$

(A.- Espinosa 2015)
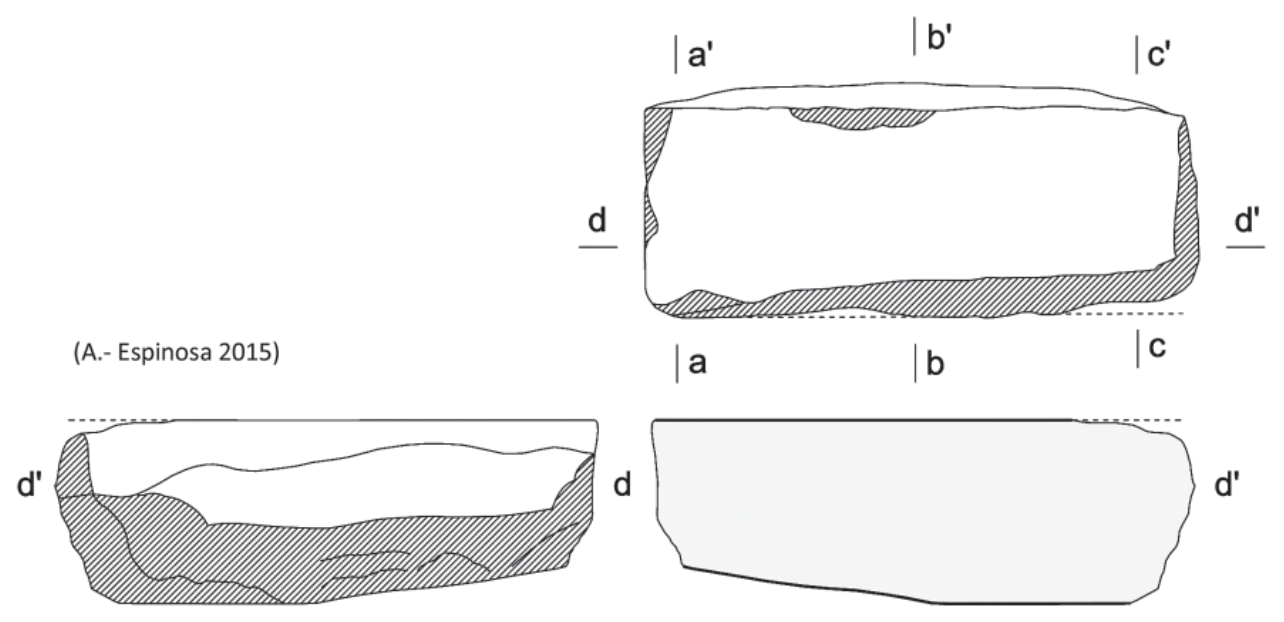

Figura 12: Sillares C y D.

con retratos es un conjunto unitario y bien documentado en Emerita Augusta en Hispania (Edmondson, Nogales y Trillmich, 2001, 29); por lo tanto, es improbable que los monumentos que nos ocupan poseyeran alguno, aunque no podemos descartar el coronamiento en tímpano.

Otra opción es que, en vez de soportar estatuas, nuestros monumentos estuvieran rematados por una o dos columnas. Los dístilos de Zalamea de la Serena (Badajoz), o el de Sermeda, en el norte de Siria (Ruiz Osuna, 2009, 321-327), podrían resultar paralelos a mayor escala. En la mezquita islámica de l'Almiserà, muy próxima a La Campaneta (García Gandía, 2004; García Gandía et alii, 2005), se hallaron tres fragmentos de columnas de orden toscano con basa en bisel, de las que según opinión de la profa. Sonia Gutiérrez, por sus reducidas dimensiones y sencillez resulta complicado determinar si son romanas reutilizadas. En caso de serlo, probablemente pertenecieran a un peristilo $u$ otro elemento arquitectónico de las cercanas villas de La Campaneta o Camí la Vila II y no al monumento que comentamos.

No creemos, en fin, que los sillares de l'Almiserà se puedan relacionar con algún monumento en forma de arco, del que el ejemplo más próximo es el de Cabanes (Abad y Arasa, 1988, 81-117), porque unas basas tan estrechas como las que presentamos no soportarían las tensiones laterales del monumento. 


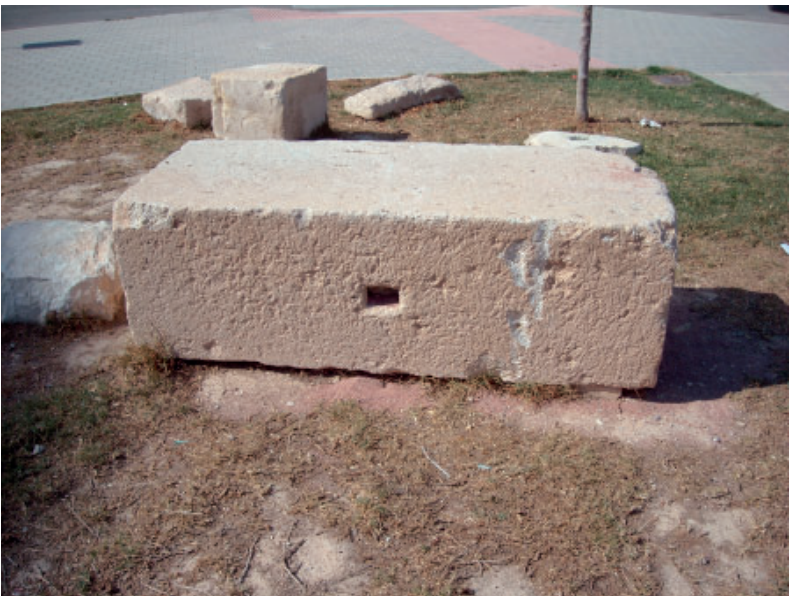

Figura 13: Sillar E (fotografía de Antonio Sellés).

A pesar de que se ha excavado ya la mayor parte del entorno de la torre hasta el terreno natural, queda sin embargo una franja en el lado este que se prevé excavar en los próximos años. Quedamos, pues, a la espera de que pueda aparecer algún fragmento más de estos pedestales durante la intervención, y será tras la misma cuando abordaremos su estudio minucioso, con el fin de ofrecer una información y una restitución lo más completas posible.

Hemos barajado diferentes hipótesis para el asombroso parecido entre las piezas de l'Almiserà y de la Torre de Sant Josep, como que se trata de pedestales realizados por el mismo taller hacia mediados del s. II; o, incluso, que el área de influencia de La Campaneta llegase hasta la playa del Torres y varios monumentos similares fuesen encargados por un mismo personaje: unos para el recinto funerario de la torre y otros para una necrópolis próxima a su residencia rural (la villa de La Campaneta). No obstante, llegados a este punto la hipótesis más sencilla y a la vez más lógica se perfila con claridad:

- Tenemos piezas molduradas pertenecientes muy probablemente a dos pedestales diferentes en l'Almiserà y otro tanto sucede en el entorno de la torre.

- Los sillares de l'Almiserà se corresponden solo con zócalos y los de la torre solo con cornisas.

- La anchura del cuerpo intermedio (dado) de las piezas es, además, idéntica en todas ellas, y coincide con el del sillar E, localizado en los sondeos para la instalación del gasoducto, que podría ser parte del dado de uno de estos pedestales (Figs. 10 y 11).

- L'Almiserà está aguas arriba del río Torres, y por tanto el transporte desde la Torre de Sant Josep era sencillo por un antiguo camino que recorría un glacis costero continuo, pasando junto a La Campaneta en dirección al valle de Finestrat. El recorrido entre ambos puntos es corto $(2,4 \mathrm{~km})$, tiene una pendiente media muy suave (apenas el $3 \%$ ) y no presenta dificultades significativas, como barrancos o lomas (Fig. 2).

Un traslado entre la torre y l'Almiserà habría sido, por tanto, relativamente fácil. Pero, ¿cuándo se pudo producir?

Pudo suceder durante el desmontaje de la parte superior de la Torre de Sant Josep, que de acuerdo con
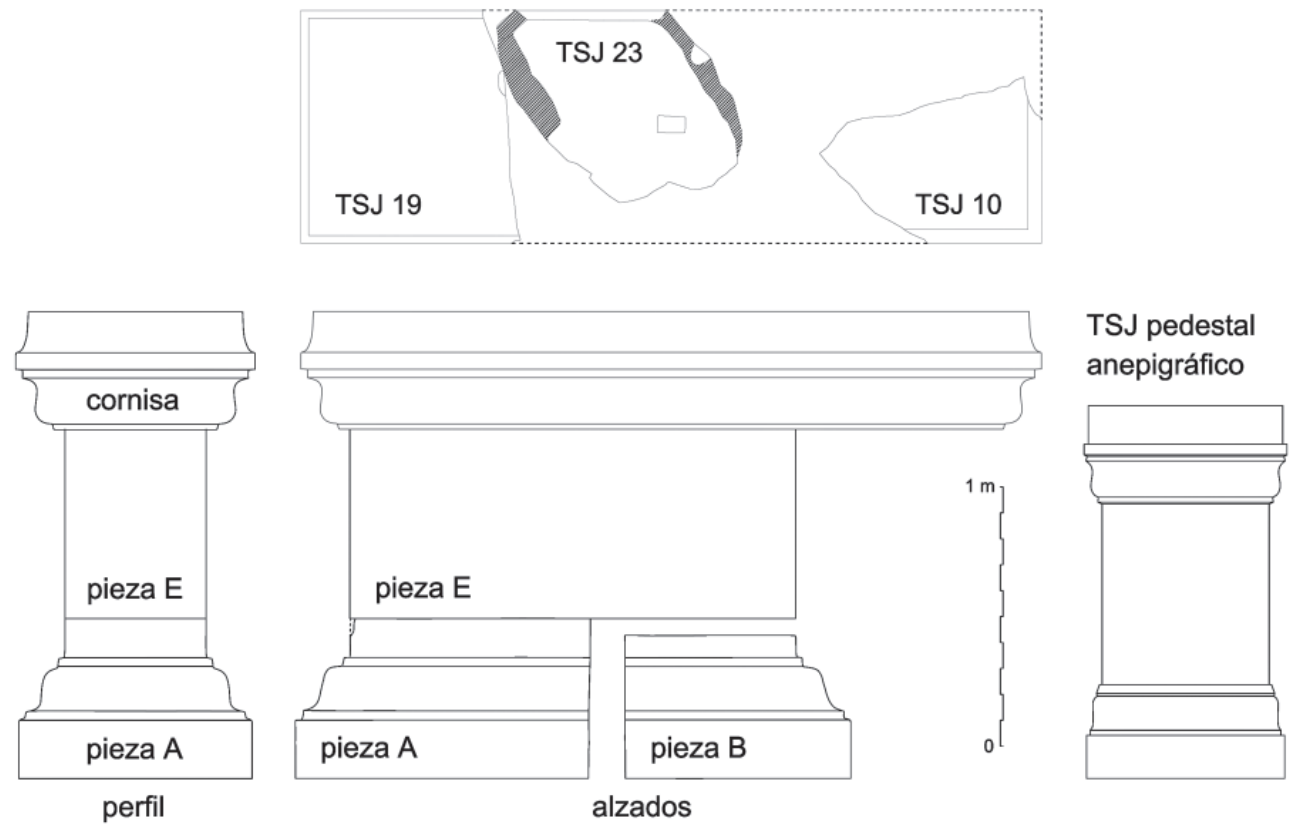

Figura 14: Composición de los sillares A, B, E y los fragmentos de cornisa de la Torre de Sant Josep TSJ 10, TSJ 19 y TSJ 23. A la derecha, pedestal anepigráfico monolítico con base y coronamiento, conservado en el entorno de la torre. Los fragmentos de cornisa y su composición hipotética, así como el pedestal monolítico, están tomados de Ruiz y Charquero (2014, 172, fig. 19). 


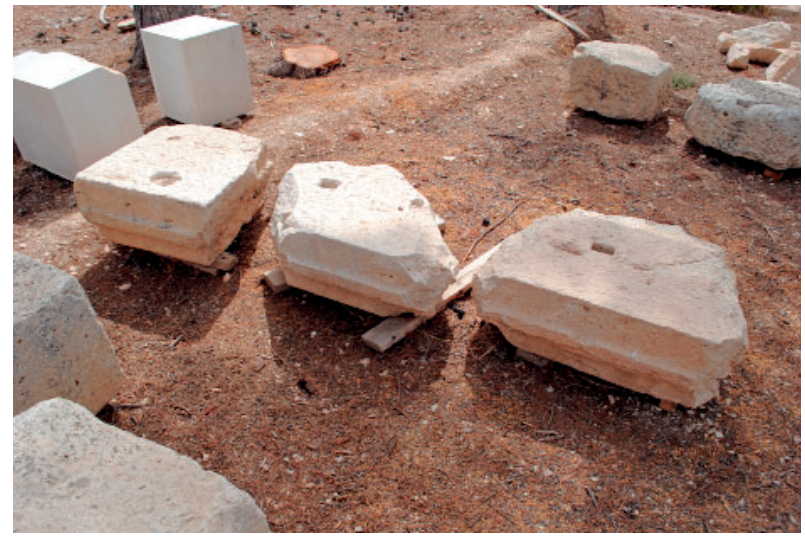

Figura 15: Tres de los fragmentos de cornisa de pedestal conservados en el entorno de la Torre de Sant Josep. En primer término se puede ver las dos piezas que presentan orificio central de suspensión, mientras el tercero presenta una huella ovalada para el anclaje de una estatua.

las noticias de Gaspar Escolano (1610-1611, libro 6 ${ }^{\circ}$, capítulo XII) ocurrió en 1543, para usar los sillares en la reconstrucción de la muralla destruida ese mismo año por un ataque corsario turco. Junto a algunos sillares de la torre se debieron llevar otros del entorno, quizá entre ellos partes de los pedestales, aunque el expolio del conjunto monumental fue incompleto ya que muchas piezas quedaron desperdigadas alrededor de la torre y más tarde reutilizadas en una casa de campo que se adosó a ella. Las cornisas de pedestal que quedaron en el lugar están deterioradas, y quizá por eso no se reutilizaron; pero los zócalos de l'Almiserà se encontraban en buen estado y, si proceden de la torre, ese pudo ser el motivo de su acarreo hasta las proximidades de La Campaneta, cuya casa de campo con torre de huerta dotada de matacanes ya debía existir en el s. XVI.

Es muy probable, por tanto, que los sillares de $L a$ Campaneta pertenezcan a los mismos pedestales funerarios de la torre. Junto con el pedestal monolítico conservado pudieron formar un conjunto de tres pedestales que originalmente estarían situados en el interior del recinto funerario descubierto en las recientes excavaciones. En la figura 14 hemos yuxtapuesto las piezas A y B a la pieza $\mathrm{E}$ y a la restitución hipotética de los tres fragmentos mayores de cornisa de pedestal que se han conservado o recuperado en el entorno de la torre (Ruiz y Charquero, 2014, 172, fig. 19), y que, como hemos dicho, según Diego Ruiz y Ana Charquero podrían corresponder a dos pedestales diferentes (ver el artículo de estos autores en este mismo número de la revista Lucentum), como sucede con las piezas de l'Almiserà.

Los sillares $\mathrm{C}$ y $\mathrm{D}$ de l'Almiserà presentan restos de almohadillado, como los de la hilada inferior de los escalones de la torre, en los que tiene una función de anatirosis y no estética, ya que la parte almohadillada quedaba oculta bajo tierra; pero no está claro, por el momento, si estos sillares almohadillados de l'Almiserà encajan en el entorno de la torre, por lo que quizá perteneciesen a la propia villa rural de $\mathrm{La}$ Campaneta o a algún monumento próximo, ya que abundan los restos de sillares en la zona.

\section{EL BLOQUE DE L. TERENCIO MANCINO, PROBABLE INSCRIPCIÓN DE LA TORRE DE SANT JOSEP}

La hipótesis de la pertenencia de los sillares moldurados a dos monumentos funerarios del entorno de la Torre de Sant Josep nos ha llevado de forma lógica a otra pregunta: ¿podría haberse trasladado a la zona de La Campaneta algún otro elemento de la torre o de su entorno? De hecho, había una pieza que no acababa de encajar en una tumba convencional, sino que claramente debía pertenecer a un gran monumento funerario de sillería, tanto por el tamaño y disposición de sus letras como por poseer solo una cara pulida y el resto solo desbastado, lo que es característico de los bloques funerarios, al ir encastrado en la estructura arquitectónica (Cebrián, 2000, 101): nos referimos a la inscripción de Lucio Terencio Mancino.

Si el llamado «monumento de l'Almiserá» se desvanecía para integrarse en el entorno de la Torre de Sant Josep, la inscripción dedicada a Mancino se quedaba como un testimonio monumental aparentemente aislado. ¿No podría «bajarse» también a la torre junto con los elementos de pedestal? ¿No se transportaría desde la torre hasta la partida de l'Almiserà junto con ellos? Tengamos en cuenta que la posible fecha que hemos barajado para un traslado de estos elementos es mediados del s. XVI, en pleno Renacimiento, una época en la que las inscripciones y testimonios de época romana constituyen un signo de distinción y cultura, y como tales son muy apreciados por las familias principales a las que pertenecen los grandes caserones repartidos por el término, entre los que se cuentan el Mas de l'Almiserà y el Mas de la Campaneta. Sabemos por una inscripción que estaba en una pared del primero de ellos -hoy conservada en Vilamuseu- que un tal Bertomeu Aragonés compró esta heredad en 1591, por lo que la casa ya existía con anterioridad.

Las mediciones que hemos realizado dejan pocas dudas sobre la pertenencia a la torre: la altura del bloque de caliza de Buixcarró que contiene la inscripción de Terencio Mancino es exactamente la misma que la de la hilada $7^{\text {a }}$ de la Torre de Sant Josep $(68 \mathrm{~cm})$, que es, junto con la $6^{\text {a }}$, una de las dos en las que podría encajar el epígrafe teniendo en cuenta su grosor (el del epígrafe es $22 \mathrm{~cm}$; y el fondo libre de la pared de la torre en esta cara, es decir, el fondo del hueco en el que podía encajar, es de entre 30 y $32,5 \mathrm{~cm}$ ) (Fig. 16).

La hilada $7^{\mathrm{a}}$ es, como decimos, la única de estas dos cuya altura coincide exactamente con la del epígrafe (la hilada $6^{\mathrm{a}}$ es $1 \mathrm{~cm}$ más alta, es decir, mide 69 $\mathrm{cm})$. En cuanto a la cara en la que se encontraba, solo puede tratarse de la norte o la sur por el mismo motivo, 

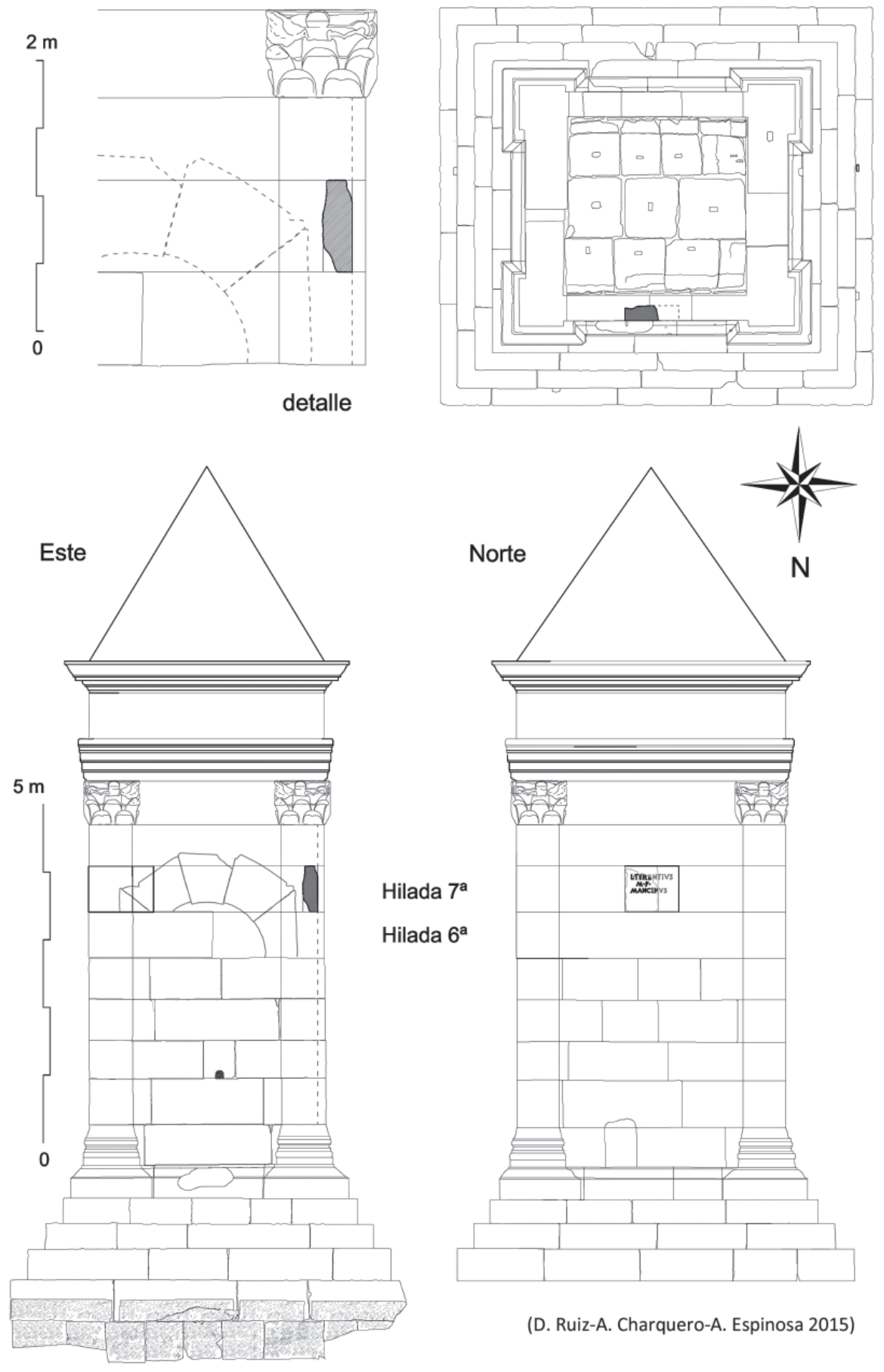

(D. Ruiz-A. Charquero-A. Espinosa 2015)

Figura 16: Inscripción de la casa de l'Almiserà presentada en el alzado norte, en la sección norte-sur y en planta de la Torre de Sant Josep (tomadas de Ruiz y Charquero, 2014). Agradecemos a Diego Ruiz y Ana Ma Charquero que nos hayan facilitado los dibujos más recientes de la torre.

ya que en las caras este y oeste el fondo de la pared del monumento es mucho mayor $(62 \mathrm{~cm})$ que el del epígrafe. La cara de la que procede debe ser la norte por tres razones:

- Era la que se veía desde el camino que bajaba desde la calzada que recorría por la llanura litoral el territorio de Allon.

- Al sur de la torre había un talud que impediría su lectura desde una distancia razonable.
- Los dos lados de la torre que daban a un espacio más ancho del recinto funerario eran el oriental y el septentrional.

En cuanto a la cronología de la inscripción, ya hemos comentado más arriba las diferentes propuestas de Josep Corell y Manuel A. Rabanal-Juan Manuel Abascal: comienzos del s. I para el primero y s. II para los segundos, opinión esta última respaldada por Rosario 
Cebrián. Esta es precisamente la fecha de la Torre de Sant Josep, que podría situarse entre 150 y 170 , si combinamos la datación del segundo tercio del s. II propuesta por Lorenzo Abad y Manuel Bendala para el monumento con una fuente de TS africana A del tipo Hayes 26 que se halló bajo el estrato de amortización de una artesa para amasar mortero de cal para el opus caementicium de la obra de la torre (Ruiz y Charquero, 2014, 176), que aporta una fecha post quem de 150. Nos situamos, pues, entre la última década de reinado de Antonino Pío y la primera de Marco Aurelio.

La paleografía de la inscripción no desdice esta datación, como tampoco el material empleado, ya que la caliza de Buixcarró se abre paso en el mercado regional a partir de mediados del s. I y sobre todo en el s. II (Cebrián, 2000, 95; Cebrián y Escrivà, 2001). Al faltar la parte derecha del bloque, no tenemos los finales del nomen ni del cognomen, y nos falta la filiación. Aquellos no son de interpretación problemática (Terentius y Mancinus), pero de ésta no se ha conservado ni un leve trazo. El texto está paginado a la izquierda, salvo la segunda línea, que debió estar centrada respecto a la primera, como se puede ver en un intento de restitución de parte del texto faltante que hemos hecho en la figura 5.

Una vez argumentada la procedencia de la inscripción de la Torre de Sant Josep y la de los sillares moldurados del entorno de este monumento, cabe preguntarse por qué la primera se empotró en la fachada de la casa de l'Almiserà y los segundos quedaron al pie de la cresta sobre cuyo escarpe se alza la casa de La Campaneta, situada a $800 \mathrm{~m}$ de camino al sur (Fig. 2). Aquí nos movemos en el terreno de las conjeturas: es posible que cada uno de los propietarios de ambos caserones decidiera hacerse con una parte diferente de los sillares repartidos alrededor de la torre tras su demolición parcial; o que ambas casas perteneciesen a un mismo dueño; o incluso que el gran peso de las piezas impidiera superar la cuesta que salva la terraza sobre la que se elevaba la villa romana y más tarde el mas de La Campaneta, lo que obligara a depositarlas a los pies de este caserón, al sur del mismo, donde más tarde se construiría la autopista. Sea como fuere, es de justicia concluir reconociendo la importancia del traslado y recuperación de estas pesadas piezas durante las obras de la autopista en los años setenta, y su posterior donación a Vilamuseu por Jaume López Lloret y Magdalena Zaragoza Lloret.

\section{CONCLUSIONES}

La gran potencia estratigráfica constatada en los sondeos para el trazado del gasoducto, mencionados más arriba; la abundancia de material arqueológico en superficie; la existencia de numerosos sillares, elementos de columnas y restos de estructuras por los alrededores, las noticias sobre una necrópolis y la existencia de epigrafía funeraria en las proximidades hacen pensar en un núcleo de cierta entidad en La Campaneta, estructurado probablemente en torno a una rica villa rural, como otros vici de la comarca. No obstante, es muy probable que los sillares hasta ahora conocidos como «monumento de l'Almiserá», partes de dos zócalos de pedestal moldurados, procedan del interior del recinto funerario de la Torre de Sant Josep, donde pudieron formar parte de dos pedestales de los que se conservan junto a la torre cuatro grandes fragmentos de cornisa.

Respecto a la inscripción de Lucio Terencio Mancino, conservada durante siglos en la fachada de la casa de l'Almiserà, tenemos pocas dudas sobre su pertenencia a la torre, y por tanto nos informaría del nombre del difunto allí enterrado.

Todo parece indicar que la después conocida probablemente como Torre de Josa (por Vilajosa, una forma contraída antigua de Vilajoiosa) y después Torre de Josep, de Sant Josep y finalmente de Hércules (por el apellido del que fue uno de sus últimos propietarios) era, pues, la Torre de Mancino, lo que supondría un hito insospechado en nuestro conocimiento de uno de los monumentos funerarios más relevantes conservados en la Península Ibérica.

\author{
Antonio Sellés Rodríguez \\ C/ Colón, $104,2^{\circ} \mathrm{D}$ \\ 03570 Villajoyosa \\ antonio_selles@hotmail.com \\ Dr. Antonio Espinosa Ruiz \\ Vilamuseu. Red de Museos y Monumentos \\ de Villajoyosa \\ C/ Colón, 57 \\ 03570 Villajoyosa \\ museo@villajoyosa.com
}

\section{BIBLIOGRAFÍA}

ABAD CASAL, L. y BENDALA GALÁN, M., 1985: «Los sepulcros turriformes de Daimuz y Villajoyosa: dos monumentos romanos olvidados», Lucentum IV, 147-184.

ABAD CASAL, L. y ARASA GIL, F., 1988: «El arco romano de Cabanes (Castellón)», Archivo Español de Arqueología, 61, 81-117.

ABASCAL PALAZÓN, J. M. y ESPINOSA RUIZ, U., 1989: La ciudad hispano-romana. Privilegio y poder, Logroño.

ABAD CASAL, L. y ABASCAL PALAZÓN, J. M., 1991: Textos para la Historia de Alicante. Edad Antigua, Alicante.

ABASCAL PALAZÓN, J. M., ALFÖDY, G. y CEBRIÁN FERNÁNDEZ, R., 2011: Segobriga V: inscripciones romanas (1986-2010), Madrid.

ADAM, J. P., 2002: La construcción romana. Materiales y técnicas, León.

$\mathrm{AE}=$ L'Année Épigraphique

ALFÖLDY, G., 2003: «Administración, urbanización, instituciones, vida pública y orden social», en J. M. Abascal y L. Abad (coord.), Las ciudades y los campos de Alicante en la época romana, Canelobre 48, 35-58. 
ARASA I GIL, F., 2011: «El Vilar (el Puig). La vil·la de F. Caecilius Rufus», en Actes del III Congrés d'Estudis de L'Horta Nord, vol. 1, 49-72, Valencia.

ANÓNIMO, 1846: «Antigüedades» en El Español: diario de las doctrinas y de los intereses sociales, época $2^{\mathrm{a}}$, número 745, 29 de noviembre, 1.

BELDA DOMÍNGUEZ, J., 1946: «Ingresos procedentes del cerrillo de Torre la Cruz, Villajoyosa (Alicante)», MMAP, VII, 143-153.

BELDA DOMÍNGUEZ, J., 1947: «Ingresos procedentes de Torre la Cruz (Villajoyosa, Alicante)», MMAP, VIII, 167-186.

BELDA DOMÍNGUEZ, J., 1948: «Nuevos ingresos procedentes del cerrillo de Torre la Cruz (Villajoyosa)», MMAP, IX, 167-172.

BELDA DOMÍNGUEZ, J., 1953: «Descubrimientos arqueológicos de Villajoyosa (Alicante): la villa romana de la Encina», Revista de Formación, 29, 20 ss.

CARBONELL ms. 1492 = CARBONELL, M. (ms. 1492): Adversaria (sive Miscellanea). Ms. 69 del Archivo Capitular, Gerona.

CEÁN BERMÚDEZ, J. A., 1832: Sumario de las antigüedades romanas que hay en España, Madrid.

CEBRIÁN FERNÁNDEZ, R., 2000: Titulum Fecit. La producción epigráfica romana en las tierras valencianas, Madrid.

CEBRIÁN FERNÁNDEZ, R., y ESCRIVÀ CHOVER, I., 2001: «La piedra de Buixcarró en las obras públicas de Valentia», Saguntum, 33, 97-110.

CHABÁS LLORENS, R., 1889: El Archivo: revista literaria semanal, tomo III, cuaderno XI, julio, 262.

CHABÁS LLORENS, R., 1890a: El Archivo: revista literaria semanal, tomo IV, cuaderno III, marzo, 72.

CHABÁS LLORENS, R., 1890b: El Archivo: revista literaria semanal, tomo IV, cuaderno III, mayo, 117-118.

CIL II = HÜBNER, E., 1869-1892: Corpus Inscriptionum Latinarum II, vol. 1, Berolini; vol. 2 suppl. Berolini.

CORELL, J., 1999: Inscripcions romanes d'Ilici, Lucentum, Allon, Dianium i els seus territoris, Valencia.

COROMINES, J., 1997: Onomasticon Cataloniae, Els noms de lloc i noms de persona de totes les terres de llengua catalana, Barcelona.

EDMONDSON J., NOGALES BASARRATE T. y TRILLMICH W., 2001: Imagen y memoria: monumentos funerarios con retratos en la colonia Augusta Emerita, Madrid.

ESCOLANO, G., 1610-1611: Décadas de la historia de la insigne y coronada ciudad y reino de Valencia, Valencia.

ESPINOSA RUIZ, A., 1989: «La Vila Joiosa romana», Revista de Arqueología, 100, 29-36.

ESPINOSA RUIZ, A., 1990: «Los mosaicos de la villa bajoimperial de Torre-la Cruz (Villajoyosa, Alicante)», Cuadernos de Prehistoria y Arqueología de la Universidad Autónoma de Madrid, 219-253.

ESPINOSA RUIZ, A., 1996a: Arqueología romana de la comarca de la Marina Baixa (Alicante), Tesis Doctoral inédita, Universidad Autónoma de Madrid.

ESPINOSA RUIZ, A., 1996b: «Dos yacimientos romanos del casco antiguo de Villajoyosa (Alicante) a partir de los fondos del Museo Local. Consideraciones sobre la ubicación del municipium y su relación con el poblamiento ibérico», XXIII Congreso Nacional de Arqueología (Elche, 1995), vol. II, 187-194. Elche.

ESPINOSA RUIZ, A., 2006: «Sobre el nombre de la ciudad ibérica y romana de Villajoyosa y la ubicación del topónimo Alonís/Alonai/Allon», Lucentum, XXV, 223-248.

ESPINOSA RUIZ, A., 2008: La Vila abans de la Vila, Companyia Catalans de la Vila Joiosa, la Vila Joiosa.

ESPINOSA RUIZ, A, RUIZ ALCALDE, D. y MARCOS GONZÁLEZ, A., 2011: «El municipi romà de la Vila Joiosa i el seu territorium» en VV. AA., La Vila Joiosa: arqueologia i museu. Catálogo de la exposición, 154173, Alicante.

ESPINOSA RUIZ, A, RUIZ ALCALDE, D. y MARCOS GONZÁLEZ, A., 2014: «Allon», en M. H. Olcina Domènech, Las ciudades romanas valencianas. Actas de las Jornadas sobre Ciudades Romanas Valencianas. Actualidad de la investigación historioarqueológica, 179-198, Alicante.

ESPLUGA, X., 2009a: «Sobre la molt primera tradició epigràfica valenciana», Butlleti de la Societat Catalana d'Estudis Històrics, XX, 221-255.

ESPLUGA, X., 2009b: «Espacios, usos y formas de la epigrafía hispana en épocas antigua y tardoantigua», en Homenaje al Dr. Armin U. Stylow, Anejos del Archivo Español de Arqueología XLVIII, 135-144, Mérida.

FEJFER, J., 2008: Roman portraits in context, Walter de Gruyter, Berlín-NuevaYork.

FILONARDIANUS ms. s. XVI: $43=$ Filonardianus $(\mathrm{ms}$. s. XVI): Codex Filonardianus. Bibliotheca Regia Berolinensis. Ms. Pict. A 61 Actualmente Staatsbibliothek Preussischer Kulturbesitz. Berlín.

FRÍAS CASTILLEJO, C., 2010: El poblamiento rural de Dianium, Lucentum, Ilici y la ciudad romana de la Vila Joiosa (siglos II a. C. - VII d. C.). Bases para su estudio, Anejo a la revista Lucentum 20, Alicante.

FUCHS, W.,1960: s. v. Genio en Enciclopedia dell'Arte Antica classica e orientales, 810-816, Roma.

GALIANA SORIANO, A., 2011: Documentació histórica i bibliografía de la Marina Baixa, Associació d'Estudis de la Marina Baixa amb coedició amb Museu de la Vila, la Vila Joiosa.

GALIANA SORIANO, A., 2012: «Toponimia medieval de la Marina Baixa», Actes de la V Jornada d'Onomàstica (Dénia, 2011), 131-142, Dénia.

GARCÍA GANDÍA, J. R., LLORENS CAMPELLO, S., LUJÁN NAVAS, A., PÉREZ BOTÍ, G. y SORIANO BOJ, S., 2001: «Proyecto l'Almisserà. Prospecciones arqueológicas en el término municipal de La Vila Joiosa», Recerques del Museu d'Alcoi, 10, 125-134.

GARCÍA GANDÍA, J. R., PÉREZ BOTÍ, G. y LLORENS CAMPELLO, S., 2004: «L'Almisserà: territorio castral y espacio rural en época islámica», en F. J. Jover Maestre y C. Navarro Poveda (coord.), II Jornadas de Arqueología Medieval: De la medina a la vila (PetrerNovelda, 2003), 83-106, Alicante.

GARCÍA GANDÍA, J. R., 2005: Territorio rural islámico en la Marina Baixa, en J. M. García León, y Espinosa Ruiz, 
A. (eds.), Actas de las I Jornadas sobre la Actualidad del Patrimonio Arqueológico y Etnográfico de la Marina Baixa, 9-16, Altea.

GONZÁLEZ SIMANCAS, M., 1907-1908 (2010): Catálogo monumental y artístico de la provincia de Alicante. 1907-1908. Edición facsimilar, Alicante.

HEp = Hispania Epigraphica

LLORENTE, T., 1889: Valencia. Sus monumentos y artes. Su naturaleza e historia. $2^{\circ}$ volumen (1887-1889), Valencia.

MARTÍ MIQUEL, I., 1877: Historia de Villajoyosa. Manuscrito original conservado en el Museu de la Vila Joiosa, escrito en 1877 y corregido y ampliado entre 1919 y 1922 por el autor. Edición y transcripción de A. Galiana Soriano, F. Martínez Zaragoza y A. Espinosa Ruiz, inédito.

OLCINA, M., 1990: «Partida de Torres», en Excavacions arqueologiques de salvament a la Comunitat Valenciana (1984-1988), Intervencions rurals, 91-93, Valencia.

PÉREZ BAYER, F., 1998: Francisco Pérez Bayer: viajes literarios, edición de Antonio Mestre Sanchis, Pablo Pérez García, Jorge Antonio Catalá Sanz, Valencia.

RABANAL ALONSO, M. A. y ABASCAL PALAZÓN, J. M., 1985: «Inscripciones romanas de la provincia de Alicante», Lucentum, IV, 191-294.

RIBERA I LACOMBA, A., 1983: La arqueología romana de Valentia: informe preliminar, Ayuntamiento de Valencia.
RUIZ ALCALDE, D. y MARCOS GONZÁLEZ, A., 2005: «La Jovada I y II, Villas altoimperiales y tardorromanas, Villajoyosa (Alicante)», en Actuaciones Arqueológicas en la Província de Alicante 2005, edición en CD-ROM de la Sección de Arqueología del Ilustre Colegio Oficial de Doctores y Licenciados en Filosofía y Letras y en Ciencias de Alicante, Alicante.

RUIZ ALCALDE, D., 2010: Las termas públicas del municipium romano de Villajoyosa, Memoria de Licenciatura, inédita.

RUIZ ALCALDE, D. y CHARQUERO BALLESTER, A. $\mathrm{M}^{\mathrm{a}}$., 2014: «El monumento funerario romano de la torre de Sant Josep de Villajoyosa (Alicante). Nuevos datos y propuesta de restitución», Lucentum, XXXIII, 151-182.

RUIZ OSUNA, A. B., 2009: Topografía y monumentalización funeraria en Baetica: Conventus Cordubensis y Astigitanus, Córdoba.

SEBASTIÀ LÓPEZ, V., 2013: Proyecto de regeneración de la playa de La Antoneta en el T.M. de La Vila Joiosa. Proyecto fin de carrera. Univ. Politécnica de Valencia. Escuela Técnica Superior de Ingenieros de Caminos, Canales y Puertos, inédito.

VALCÁRCEL, A., 1852: Inscripciones y antigüedades del Reino de Valencia, Madrid.

VAQUERIZO GIL, D., 2010: Necrópolis urbanas en Baeti$c a$, Serie Documenta 15, Tarragona.

Recepción: 01-06-2015

Aceptación: 05-10-2015 